\section{organic} communications

\title{
Click chemistry: a fascinating method of connecting organic
} groups

\author{
Bibi Amna $\oplus^{1,2}$ and Turan Ozturk $\oplus^{* 2,3}$ \\ ${ }^{1}$ Department of Chemistry, Quaid-i-Azam University, Islamabad 45320, Pakistan \\ ${ }^{2}$ Istanbul Technical University, Department of Chemistry, 34469 Maslak, Istanbul, Türkiye \\ ${ }^{3}$ TUBITAK-UME, Chemistry Group of Laboratories, PO Box 54, Gebze, Kocaeli 41471, \\ Türkiye
}

(Received March 16, 2021; Revised April 24, 2021; Accepted April 25, 2021)

\begin{abstract}
Click chemistry, a modular synthetic strategy for synthesizing the assembly of novel molecular entities, has made a tremendous impact in the field of science since its debut. This powerful strategy relies mainly upon the construction of carbon-heteroatom bonds using spring-loaded reactants. Its growing number of applications are found in nearly all areas of modern chemistry ranging from drug discovery to materials science. This manuscript includes important aspects of the copper-catalyzed Huisgen cycloaddition reaction, which is considered a gold standard of click chemistry due to its biocompatibility and reliability, along with its applications in bioconjugation, drug delivery and polymer chemistry. A bird's eye view of recent progress in developing the copper-free click chemistry protocols such as catalyst-free strain-promoted alkyne-azide cycloaddition (SPAAC) click chemistry has also been provided.
\end{abstract}

Keywords: Click chemistry; Huisgen 1,3-dipolar cycloaddition; drug delivery; bioconjugation. @2021 ACG Publications. All right reserved.

\section{Introduction}

The term "click chemistry" was first introduced by Dr. Barry Sharpless group in 1999 at the $217^{\text {th }}$ American Chemical Society annual meeting, ${ }^{1}$ later in 2001, Kolb, Finn and Sharpless, in their land mark review, described it as concept for conducting organic reactions, which was based upon the premise that organic synthesis should focus attention on highly selective, simple orthogonal reactions that give heteroatom-linked molecular systems with high efficiency under mild reaction conditions. ${ }^{2}$ Several efficient reactions, which are capable of producing a wide catalogue of functional synthetic molecules and organic materials have been grouped accordingly under the term click reactions. The rule of thumb for this approach was that "... all searches must be restricted to molecules that are easy to make".

Click chemistry concerns with a generation of the substances by joining small, selective and modular building blocks together with heteroatom links (C-X-C). These building blocks contain a high built-in energy content that drives a spontaneous and irreversible linkage reaction with complementary sites in other blocks and work reliably in both small- and large-scale applications. Click Chemistry dictates a "guiding principle"- A principle born to meet the demands of modern day chemistry.

In order to reach up to a status of click reaction, a process must fulfil certain conditions. Reaction must be

a) modular

b) with wider scope

c) high yielding

*Corresponding author:E-Mail: ozturktur@itu.edu.tr

The article was published by ACG Publications

http://www.acgpubs.org/journal/organic-communications @ April-June 2021 EISSN:1307-6175

DOI: http://doi.org/10.25135/acg.oc.100.21.03.2006 
d) generating only harmless byproducts which could be removed easily by employing nonchromatographic methodologies

d) stereospecific (but not necessarily enantioselective)

e) under milder reaction conditions (ideally insensitive to air and water)

f) conducted with readily available starting materials and reagents

g) under either no or some benign solvent

h) generating stable product under physiological conditions

e) orthogonality with other common organic synthesis reactions

Carbon-heteroatom bond forming reactions comprise the most common examples (Scheme 1), including the following classes of chemical transformations:

a) nucleophilic ring opening reactions: epoxides, aziridines, aziridinium ions etc. ${ }^{2}$

b) non-aldol carbonyl chemistry: formation of ureas, oximes and hydrazones etc.

c) additions to carbon-carbon multiple bonds: especially oxidative reactions such as aziridation, ${ }^{3}$ hydroxylation, ${ }^{4}$ epoxidation, ${ }^{5}$ nitrosyl and sulfenyl halide additions, ${ }^{6}$ and Michael additions of $\mathrm{Nu}-\mathrm{H}$ reactants.

d) Cycloaddition reactions: especially 1,3-dipolar cycloaddition reactions as well as hetero- Diels-Alder reactions. $^{7-9}$

\section{Cycloadditions}

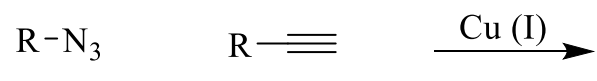

Nucleophilic Ring Openings<smiles>[Y]C1CC1CC[NH]</smiles>

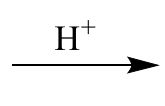<smiles>[R]c1cn([R])nn1</smiles>

Non-Aldol Carbonyl Chemistry<smiles>[R]C([R])=O</smiles><smiles></smiles><smiles>[Y1]CC[NH]</smiles>

(Hydrazone/oxime ether formation)

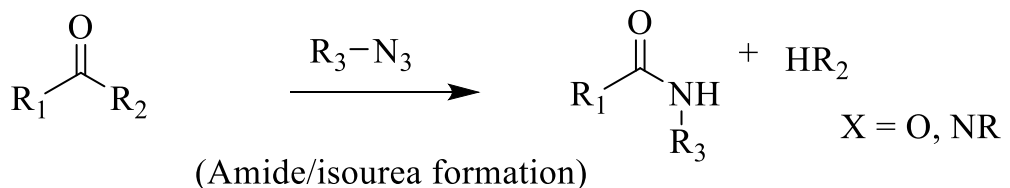

\section{Carbon multiple bond additions}

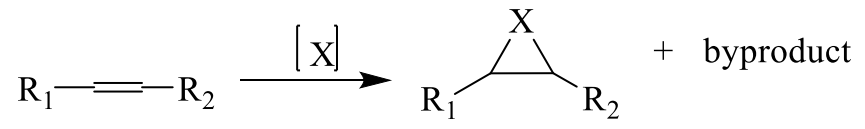

(Formation of various three member rings)

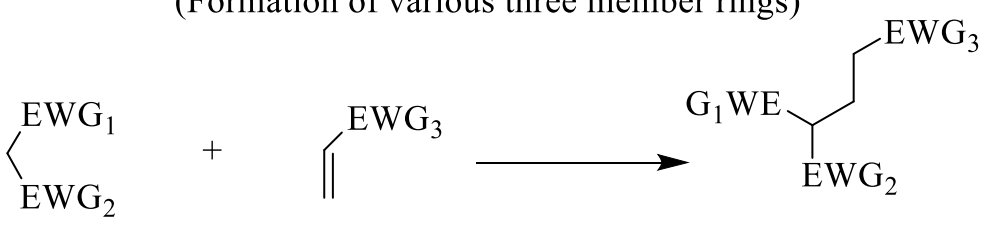

(Certain Michael additions)

Scheme 1. Summary of the most popular click reactions 
Amongst all the reactions which achieve "click status", the Huisgen 1,3-dipolar cycloaddition of alkynes and azides to yield 1,2,3-triazoles is undoubtedly the premier example of a click reaction. ${ }^{10-14}$ The most primitive azide-alkyne cycloaddition was explored by Huisgen and coworkers during 1950-70s. Although the reaction was highly exothermic with low reaction rate and yield, it had a great impact on further research. The requirement of high temperature and pressures for this reaction were the biggest constraint for its application in living systems. It was not that popular until the use of copper as a catalyst, which solved this issue. The discovery of the $\mathrm{Cu}(\mathrm{I})$ catalyzed azide-alkyne cycloaddition in 2002 (Scheme 2) transformed CC from a working concept to an accepted reality. This reaction is usually conducted under mild conditions using diverse available substrates, highly yielding 1,4-regioisomers of 1,2,3- triazoles as sole products instead of regiorandom triazole adducts which complies fully with the definition of the conceptual click chemistry. This "near perfect" reaction has become synonymous with CC, and is often referred to as "The Click Reaction". This water-tolerant reaction is thermodynamically favorable by approximately $30-35 \mathrm{kcalmol}^{-1}$.

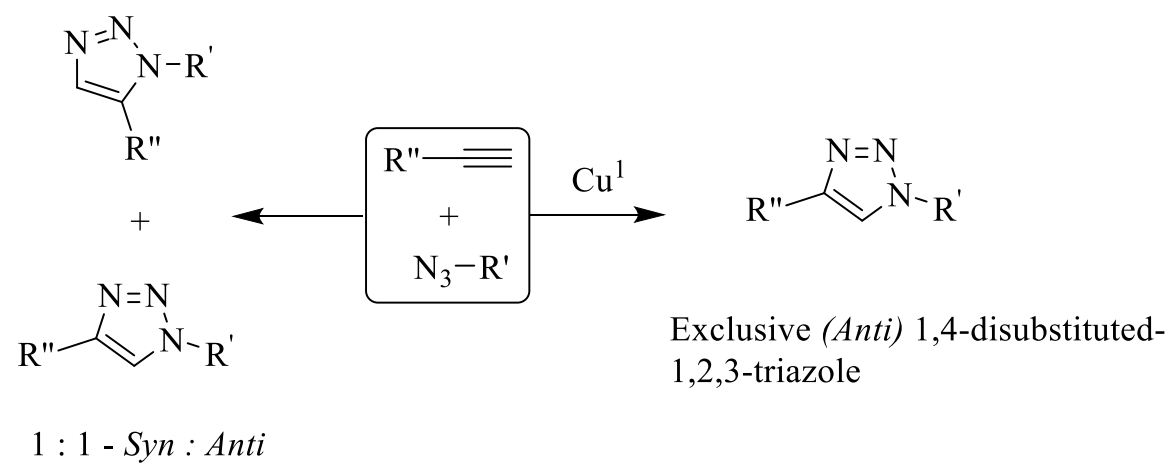

Scheme 2. The $\mathrm{Cu}(\mathrm{I})$ catalyzed Huisgen 'click reaction' results in exclusive formation of 1,4-triazole, whilst the thermally induced Huisgen cycloaddition usually results in an approximately $1: 1$ mixture of 1,4- and 1,5-triazole stereoisomers

Over the past five years, it has been observed that the very best click reaction classes proceed most rapidly and in highest yield, not in water or water-co-solvent mixture ${ }^{15}$ but floating on water. ${ }^{1}$ For instance, 1,3-dipolar cycloadditions between diethyl acetylenedicarboxylate and diazidocyclohexanediols proceed best in pure water. ${ }^{1}$ When water is omitted so that the above reactants are mixed neat, the reactions are much slower and less selective, and, on a larger scale, become dangerous, as click chemistry reactions are highly exothermic. The presence of water in these reactions is beneficial, not just for reactivity but also because water is the best heat-sink for handling the enormous heat output when click reactions are performed on larger scales. Another advantage of employing water as a reaction solvent is that its presence prevents interference from simple protic functional groups, like amides and alcohols, which are enormously present in biologically active organic molecules. ${ }^{16}$

The advent of click chemistry has had a profound influence on almost every branch of chemical science and it has become a ubiquitous chemical tool with applications in nearly all areas of modern chemistry from chemical to material science. An overview of the recent advancements of click chemistry in different fields have been given below.

\section{Bioconjugation}

Bioconjugation encompasses a broad arena of science at the interface between chemistry and molecular biology, involving the formation of covalent links between synthetic labels and biomolecular frameworks. It involves biocompatible reactions joining substrates to biomolecules in a selective, fast and high-yielding manner. ${ }^{17}$ Covalently linking two molecular entities is a challenge for molecular biologists and chemists while studying the biological systems, for instance, attaching a small molecular probe (fluorescent dye, radical probe, affinity tag, etc.) onto a biopolymer or linking a complex carbohydrate with a peptide. Because of the diverse functional reactivity and structural complexity, one has to find out selective ligation reactions, allowing the coupling of two mutually and uniquely reactive functional 
groups, usually in an aqueous environment under physiological conditions. These functional groups should be selective for each other as well as capable to tolerate other functionalities, hence circumventing the need to use protecting groups and ideally allowing applications of the molecules in the complex environment of a living cell.

Reactions employing azide moiety as a functional group are mostly employed in bioconjugation and they are known to offer following advantages; ${ }^{18-21}$ (i) the azide moiety is absent in almost all natural existing compounds and (ii)despite a high intrinsic reactivity, azides allow selective ligation with a very limited set of reaction partners.

The Huisgen 1,3-dipolar cycloaddition of azides and acetylenes to give 1,2,3-triazoles was identified as an interesting candidate after Sharpless et al. Realization of achieving higher functional group compatibility by employing electrocyclic reactions instead of encountering limitations imposed by electrophile-nucleophile reactions. The groups of Sharpless and Finn employed the azide-alkyne coupling in the parallel synthesis of a highly active inhibitor of the enzyme acetylcholinesterase (AchE) 5. ${ }^{21}$ Sharpless and Finn chose a strategy that involved a biological target that should literally guide the inhibitor synthesis by serving as a template for the assembly of building blocks instead of using a conventional approach in which a diverse set of chemical compounds is first synthesized and subsequently screened against the biological target in question.

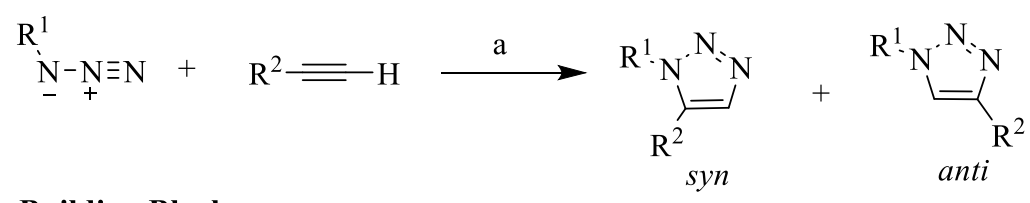

Building Blocks

Azides :<smiles>N#[W]c1c2c(nc3ccccc13)CCCC2</smiles><smiles>N=C[n+]1c(-c2ccccc2)c2cc(N)ccc2c2ccc(N)cc21</smiles>

3
Alkines :

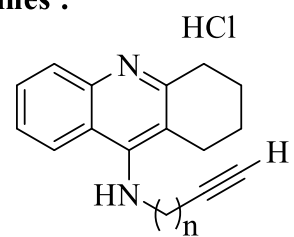

$2 \mathrm{n}=1-3$<smiles>[R9]C#[N+][n+]1c(-c2ccccc2)c2cc(N)ccc2c2ccc(N)cc21</smiles>

4

\section{Best inhibitor}<smiles>Nc1ccc2c(c1)c(-c1ccccc1)[n+](CCCCCc1cnnn1CCNc1c3c(nc4ccccc14)CCCC3)c1cc(N)ccc21</smiles>

Scheme 3. Template-guided synthesis of the highly active AChE inhibitor 1 by azide-alkyne coupling. a) AchE (0.03 equiv), $\mathrm{pH} 7.4$ buffer, RT, 49 parallel reactions

Complementary pairs of a selection of site-specific inhibitors based on tacrine and phenanthridinium motifs containing alkyl acetylenes $\mathbf{1}$ and $\mathbf{3}$ and alkyl azides $\mathbf{2}$ and $\mathbf{4}$ of different chain 
Amna and Ozturk, Org. Commun. (2021) 14:2 97-120

lengths were incubated in the presence of electrophorus $\mathrm{AChE}$ at room temperature (Scheme 3). In the absence of enzymesl rate of reaction under these conditions was negligible, hence, detectable amounts of triazole products formed only when the azide and alkyne were brought together by the enzyme, enforcing propinquity and proper alignment of the reactants. Amongst 49 reactions, only one combination yielded a detectable amount of coupled product. This substance $\mathbf{1}$ turned out to be the most potent noncovalent AChE inhibitor known, with Kd values ranging from $77 \mathrm{fM}$ (AChE from Torpedo californica) to $410 \mathrm{fM}$. The fact that azide and alkyne tags may easily be introduced into small molecules and proteins through chemical synthesis and common in vitro protein modification procedures, have revolutionized bioconjugate chemistry, particularly when $\mathrm{Cu}(\mathrm{I})$-chelating ligands are employed in the coupling reaction.

However, the low intrinsic reaction rate of the azide-alkyne coupling-key for the experiment described above, was supposed to be dramatically increased in order to make this reaction attractive as a general bioconjugation strategy. ${ }^{22}$ A catalyst was needed to be identified for accelerating the reaction as increasing the temperature was not an option due to the sensitivity of the biological materials towards heat. Catalytic amounts of $\mathrm{Cu}(\mathrm{I})$ salts was found to accelerate the rate of reaction as well as improve the regioselectivity to deliver exclusively the 1,4-disubstituted product (Scheme 4). Cu(I)-catalyzed azidealkyne coupling proved to be compatible with the numerous functional groups ${ }^{23-25}$ such as thioethers, carboxylic acids, esters, amides, ethers, thiols, alcohols, phenols, amines, guanidines and carbamates.

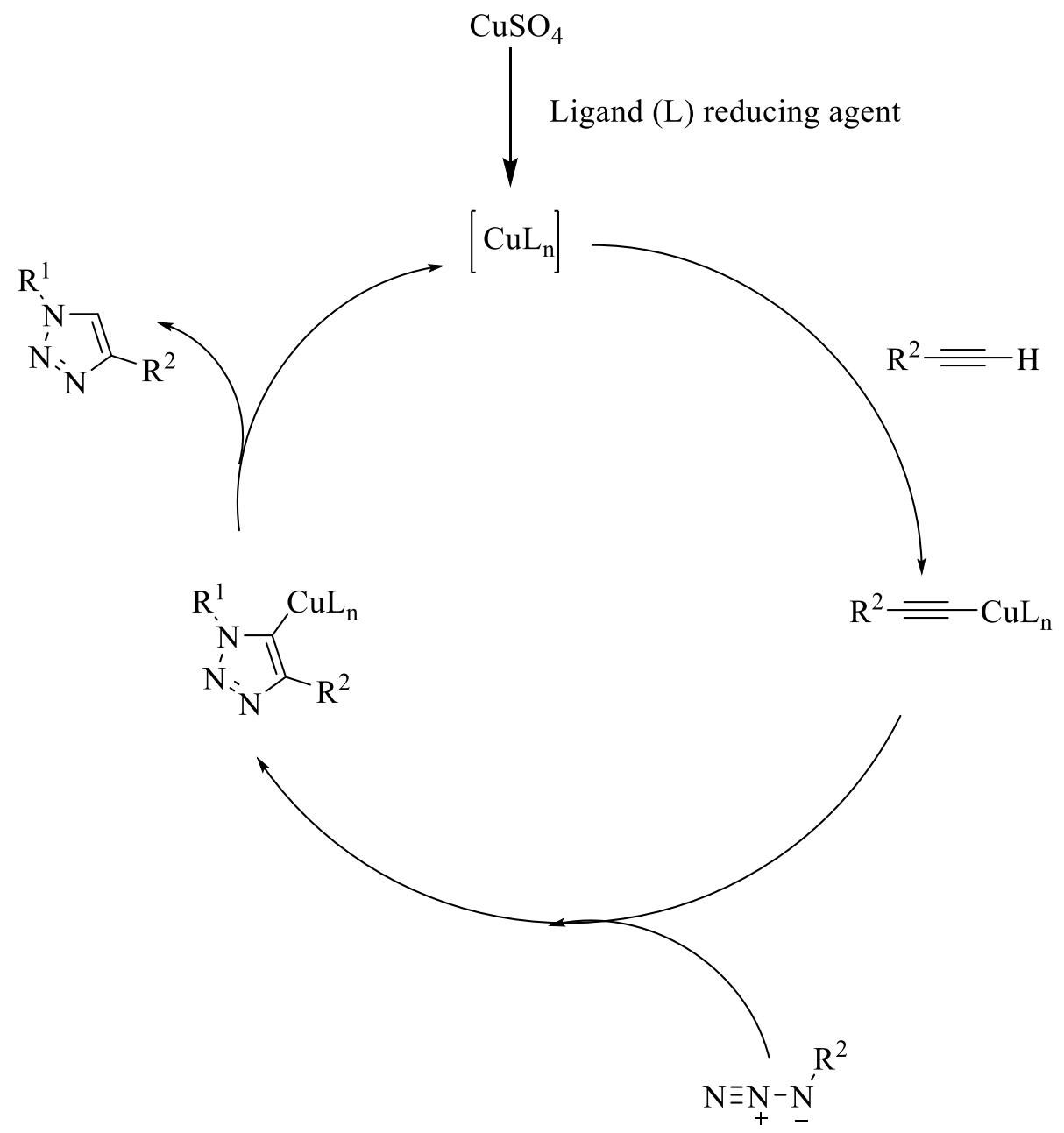

Scheme 4. Catalytic cycle of the $\mathrm{Cu}(\mathrm{I})$-catalyzed azide-alkyne coupling

Bioconjugation based on crosslinking primary amines to carboxylic acid groups has found broad applications in protein modification, nanomaterial functionalization and drug development. However, proteins tend to give nonselective bioconjugation when primary amine-based crosslinking is employed. 
Thus, selective bioconjugation is required for controlling the protein orientation and activity after conjugation.

Yuan Liu and co-workers reported an efficient and cysteine-selective thiol-ene click reaction-based bioconjugation protocol employing colloidal nanoparticles. ${ }^{26}$ The resulting thiol-ene based enzyme nanoconjugates and aptamer displayed excellent enzymatic activity and target binding ability, respectively. Colloidal nanoparticle-based bioconjugates containing manganese oxide, iron oxide and UCNP were designed and crosslinkers were tested by HS-aptamer labeling, HS-PEG Pegylation and enzyme immobilization. Thiol-ene crosslinker was found to be stable and robust by Gel electrophoresis. Furthermore, the binding ability of aptamer to its target cells or the catalytic activity of HRP enzyme was not affected by the stable and robust thiol-ene linkage between dopamine acrylamide functionalized UCNPs and aptamer or HRP. Bioconjugates based on reactions with nanomaterials have enormous potential in such fields as material sciences and biology. In particular, the stability and superior selectivity of the thiol-ene make it a potential candidate to be used in multifunctional nanomaterial bioconjugates, making this a powerful tool with broad spectrum of applications in bioimaging, bioanalysis, biosensing, drug delivery and theranostics.

Bioorthogonal reactions have revolutionized the way low-molecular-weight compounds are linked to biomolecules. Low-molecular-weight compounds are not able to evoke a secondary, adaptive immune response on their own. In order to trigger the cascade of events leading to the proliferation of plasma and memory B cells and to the production of high-affinity IgG antibodies, for these so-called haptens, the compound have to be linked to an entity carrying epitopes for helper T-cells. ${ }^{27-34}$ Proteins are the most commonly used carriers such as globulins, albumins and hemocyanins, viruslike particles, or toxoids. Formation of stable amide bonds between carboxylate groups of the hapten and amine groups of the protein has been the most extended protocol for the bioconjugation of small compounds. $N$ Hydroxysuccinimidyl esters synthesized via chemistry-mediated carbodiimides were able to efficiently react, with solvent-accessible lysine residues, which were ubiquitous in most carrier proteins, under mild reaction conditions. ${ }^{35,36}$

Daniel López-Puertollano and co-workers reported for the first time that CuAAC chemistry is a convenient approach for the preparation of protein-hapten bioconjugates intended for the generation of suitable antibodies for immunodiagnostics of small organic chemicals, using mycotoxin ochratoxin A as a model compound. ${ }^{37}$ These results revealed that the participation of the triazole moiety in antibody binding is not as critical as previously thought, hence, its presence in the spacer arm does not preclude the production of antibodies with apparent affinity constants for the analyte in the subnanomolar range. These finding opened the door for achieving highly valuable biotechnological immunoreagents for other relevant compounds, like biotoxins, antibiotics and drugs, through unexplored chemical strategies involving innovative positions for linker attachment and hapten functionalization. Further studies should certainly contribute to clarifying the generalizability of the strategy reported herein.

The primary amine is a key functional group and one of the most important nucleophiles and bases used in all of synthetic chemistry. ${ }^{38-41}$ The development of methods for conjugating a range of molecules to primary amine functional groups has revolutionized the fields of chemistry, biology, and material science. Tremendous efforts have been dedicated for the synthesis of molecules containing primary amines and methodologies to devise chemical reactions to react with primary amines. In particular, primary amines are an abundant functional group found in biological systems as free amino acids, in metabolites and signaling molecules and are also present in many classes of natural products. The primary amine is the most convenient functional group handle in molecules for ligation to other molecules for a broad spectrum of applications due to its ubiquity. ${ }^{42-46}$

Sina Elahipanah and co-workers developed a novel traceless, high-yielding, robust click-chemistry protocol based on the fast and efficient trapping of amine groups through a functionalized dialdehyde group. ${ }^{47}$ The general reaction has been shown in Scheme 5, for the conjugation of a disubstituted 1,5pentanedial 6 with a primary-amine-containing molecule 7 to form a disubstituted 1,4-dihydropyridine 8 conjugate. This click reaction was conducted under mild reaction conditions, in aqueous medium or in the presence of organic solvent and proceeded in high yield with stable starting dialdehyde reagent and resulting dialdehyde click conjugates. No dialdehyde-activating group or catalyst was needed for this reaction and only water is formed as a byproduct. Reaction proceeded with high atom economy and the 
Amna and Ozturk, Org. Commun. (2021) 14:2 97-120

starting dialdehyde and the resulting conjugate were both easy to characterize. A scheme was designed to synthesize a suite of dialdehyde reagents inorder to demonstrate the broad scope of this new clickconjugation protocol. The dialdehyde molecules were used for tailoring surfaces for material science applications and in cell-surface engineering. The broad utility of the general dialdehyde click chemistry to primary amines is anticipated in all areas of chemical research, ranging from bioconjugation and polymers to nanotechnology and material science.

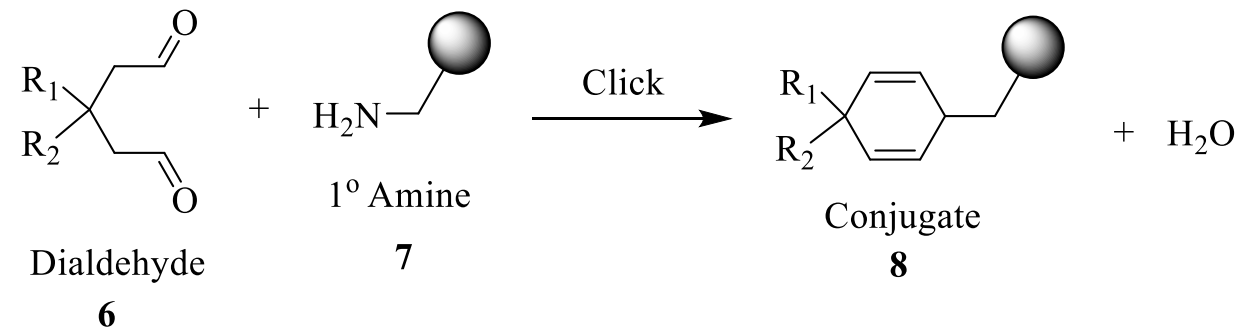

Scheme 5. Schematic of a general click-reaction strategy to ligate a primary amine group 7 with a dialdehyde group 6

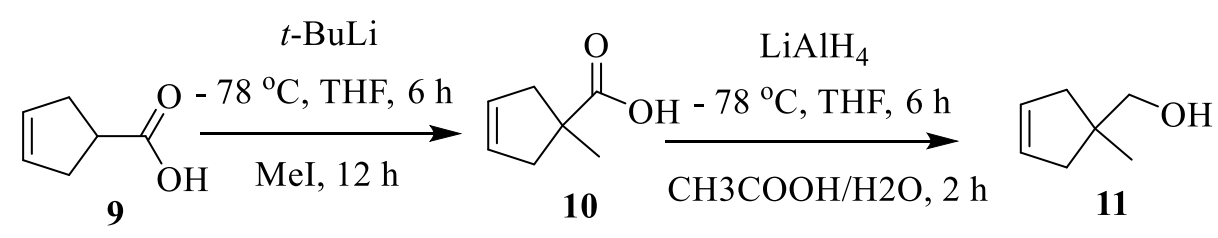

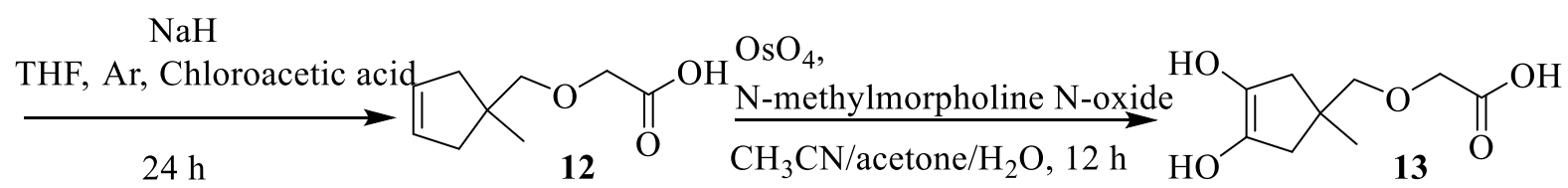<smiles>CC1(COCC(=O)O)CC2=C(C1)OC(C)(C)O2</smiles><smiles>CC1(C)CC2=C(C1)OC(C)(C)C2</smiles><smiles>NCCOCN</smiles><smiles>CC1(C)CC2=C(C1)OC(C)(COCC(=O)C(=O)O)C2</smiles>

THF, sodium bicarbonate,
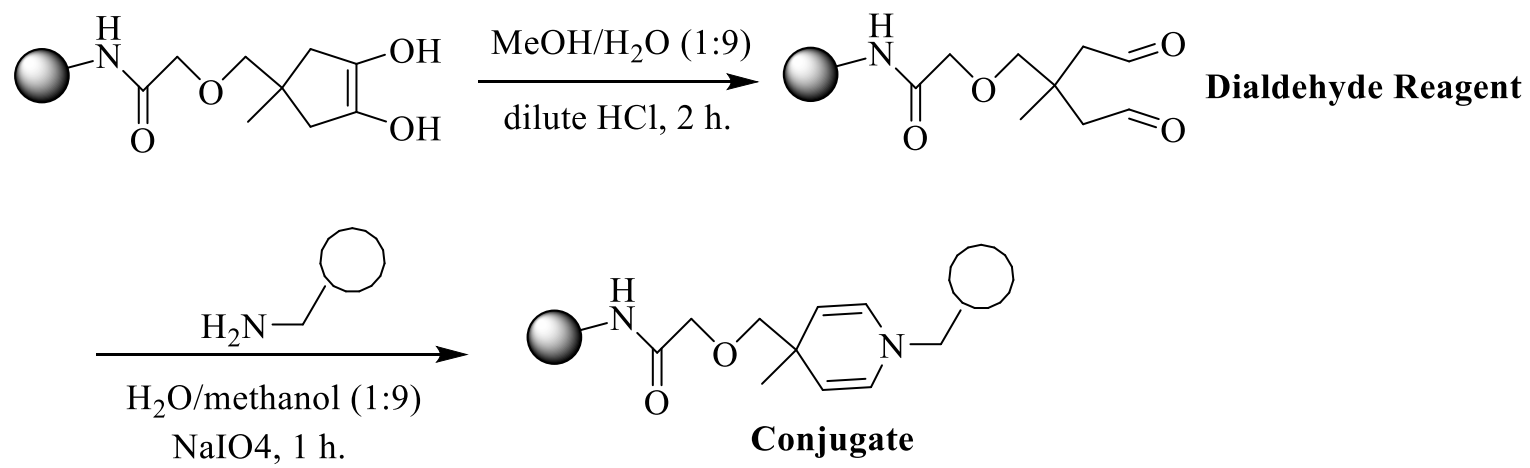

Scheme 6. Synthetic route to generating a suite of dialdehyde reagents 
The dialdehyde reagents were synthesized with minimal steps and in high yields. Acid 9 was converted to 10 in the presence of $n$-BuLi and excess of iodomethane. Alcohol 11 was obtained by treating 10 with $\mathrm{LiAlH}_{4}$. 2-((1-Methylcyclopent-3-enyl)methoxy) acetic acid $\mathbf{1 2}$ was afforded by the addition of $\mathrm{NaH}$ and 2-chloroacetic acid to 11. Catalytic amount of $\mathrm{OsO}_{4}$ and excess $\mathrm{N}$-methylmorpholine $\mathrm{N}$-oxide $50 \%$ in $\mathrm{H}_{2} \mathrm{O}$ at $\mathrm{pH} 8$, were used to obtain compound $\mathbf{1 3}$, which was subsequently converted to the key intermediate 14 employing catalytic amount of $p$ - $\mathrm{TsOH}$ and then large excess of 2,2-dimethoxypropane. 15 allowed for many dialdehyde-containing reagents to be synthesized. Once the intermediate $\mathbf{1 0}$ is obtained, a range of probes, monomers, ligands, and molecules could be connected to generate a broad suite of dialdehyde reagents (Scheme 6).

\section{Polymer Chemistry and Macromolecular Engineering}

Click reactions, being versatile and simple, can greatly facilitate the synthesis and modification of polymeric materials. There is a wide range of polymers that have been synthesized by employing various click reactions including (multi)block copolymers ${ }^{48-51}$ and micelles, ${ }^{52-56}$ terminal- and pendant-functional polymers, ${ }^{57-61}$ gels and networks, ${ }^{62-65}$ complex architectures such as graft, ${ }^{66-77}$ star, ${ }^{78-84}$ brush, ${ }^{57,85-87}$ hyperbranched polymers ${ }^{88-92}$ and polymers conjugated to nanomaterials. ${ }^{93-103}$ Many of the polymers that are used for further modifications were originally synthesized through controlled polymerization techniques. Polymers with pre-determined molecular weight, chain end functionality, narrow molecular weight distribution and controlled architecture are usually prepared by using controlled radical polymerization (CRP). ${ }^{104-106}$ The most commonly employed CRP methodologies include reversible addition-fragmentation transfer (RAFT) polymerization, ${ }^{107-110}$ atom transfer radical polymerization (ATRP) $)^{11-115}$ and stable free radical polymerization (such as nitroxide-mediated polymerization, NMP). ${ }^{116,117}$ In these strategies, composition, molecular weight and topology is controlled by a fast dynamic equilibrium between a dormant and propagating state which sustains a low concentration of radicals, hence, suppressing chain termination reactions. ${ }^{18-130}$ Click chemistry combines particularly well with these reactions because the species used to initiate polymerization or mediate the dynamic equilibrium can provide functional groups either inherently present or intentionally added that are easily converted to "clickable" functionality.

Modern polymeric material design often involves precise macromolecular synthesis in order to get macroscopic material properties of choice. This concept is referred as macromolecular engineering which includes the rational design of the macromolecular structure, accurate synthesis, assembly, and processing to nanodevices or upramolecular objects, thorough characterization, and theoretical modeling for aiding and optimizing the macromolecular design procedure. ${ }^{131}$ Precise tailoring of the molecular and supramolecular structures required for achieving desirable features such as molecular size, topology, uniformity, functionality and composition, is considered core of the macromolecular engineering. ${ }^{132} \mathrm{Click}$ chemistry is one of the available tools at researchers' disposal to tailor the molecular architectures. ATRP and $\mathrm{CuAAC}$ are often combined together in macromolecular architecture design ${ }^{133}$ due to the following reasons:

a) $\mathrm{Cu}(\mathrm{I})$ is used as catalyst in both $\mathrm{CuAAC}$ and ATRP.

b) Both azide and alkyne groups are stable during the course of ATRP as long as they do not coexist in the same reaction.

c) ATRP furnishes polymers containing halogens at their chain ends which can easily be converted to the azide groups.

Concurrent ATRP/CuAAC proved to be a very efficient tool to synthesize an array of diverse polymeric materials including brush polymers, ${ }^{134-136}$ block copolymers, ${ }^{137}$ networks ${ }^{138}$ and polymers with functional side groups. ${ }^{139,140}$

Binbin $\mathrm{Xu}$ and coworkers reported the synthesis of well-defined asymmetric molecular doublebrushes consisting of two different side chains linked to the same repeat unit along the backbone by onepot concurrent ATRP and $\mathrm{Cu}$-catalyzed azide/alkyne cycloaddition (CuAAC) reaction. ${ }^{141}$ The doublebrushes were based on a poly(Br-acrylate-alkyne) homopolymer possessing an alkynyl for CuAAC 
Amna and Ozturk, Org. Commun. (2021) 14:2 97-120

reaction and a 2-bromopropionate initiating group for ATRP in each repeat unit. Employing an acrylate type monomer containing both an ATRP initiationsite, i.e., tert-butyl 2-((2bromopropanoyloxy)methyl)acrylate (tBBPMA) and an alkyne group, was the key to the successful synthesis of Janus armed bottlebrush copolymer. This monomer tBBPMA was polymerized via RAFT to afford a polymer with two types of functional side groups on each monomeric unit. Finally, the Janus armed bottlebrush copolymer was synthesized in one-pot by concurrent ATRP of vinyl monomers and CuAAC coupling of poly(ethylene oxide) with an azide end group (PEO- $\mathrm{N}_{3}$ ) to afford well-defined copolymers with and narrow molecular weight distribution and controlled architecture (Scheme 7).

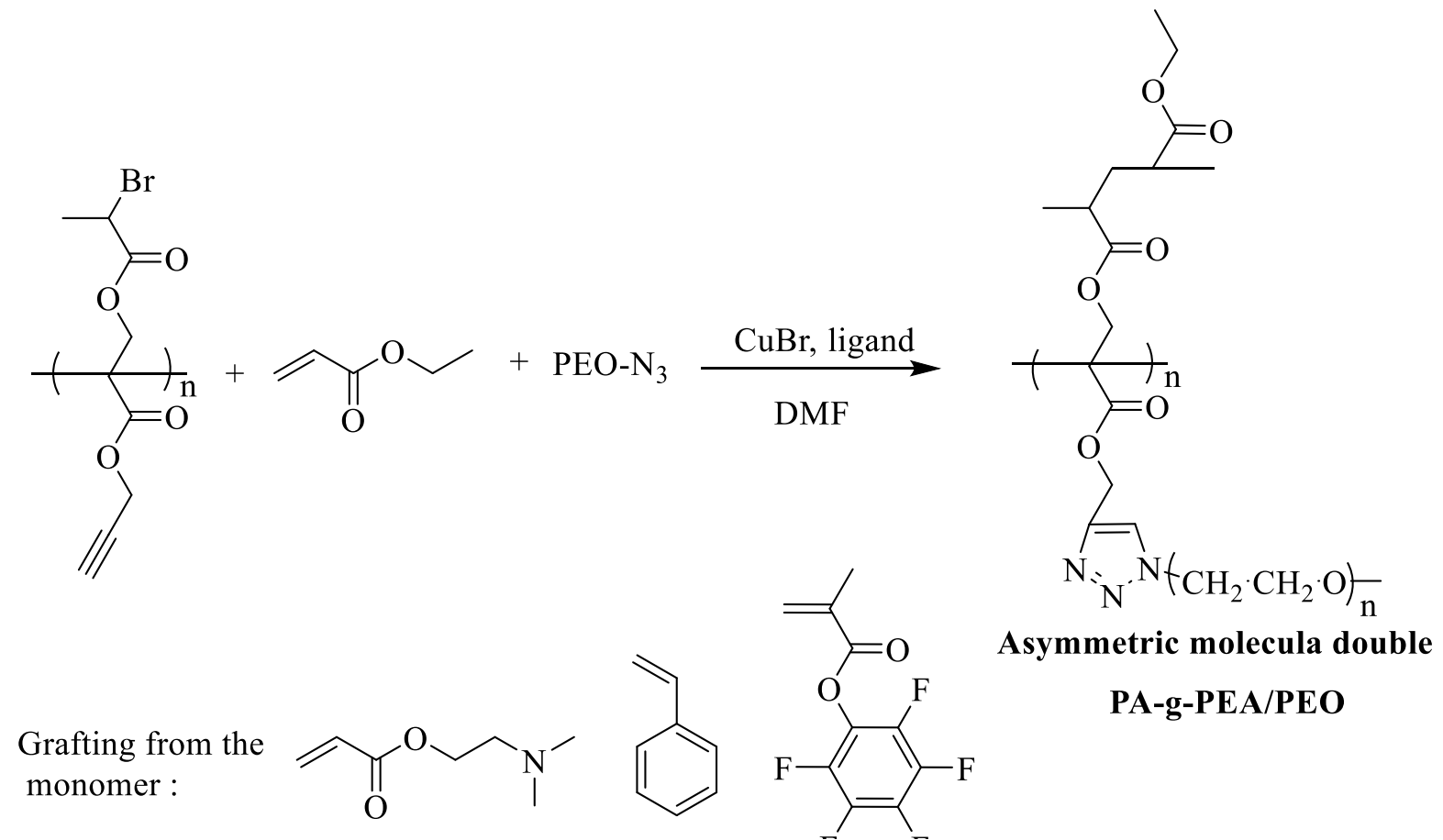

Scheme 7. Synthesis of Janus armed bottlebrush copolymer by concurrent ATRP and CuAAC click chemistry

In recent years, various researchers have reported number of excellent examples which involved $\mathrm{CuAAC}$ reactions to design functional materials with improved properties. However, the majority of previous investigations utilized CuAAC reactions alone or multistep reactions; the controlled chaingrowth CuAAC polymerization has rarely been reported because it was hard to be well-controlled and furnished polymers with broad molecular weight distribution. Recent developments in the electron transfer mediated controlled/“living" radical polymerization (CRP) facilitated the further development of the $\mathrm{CuAAC}$ reactions because the mechanisms of CuAAC reactions and CRP may have little in common using the same copper(I)-catalyst for both protocols.

Wentao Xue and co-workers successfully employed the electron transfer mediated "click- radical" concurrent polymerization utilizing $\mathrm{Cu}(0) / \mathrm{PMDETA}$ as catalyst for the generation of well-defined copolymers, where controlled CuAAC polymerization of clickable ester monomer was performed in the main chain acting as the polymer backbone, the CRP of the acrylic monomer was conducted in the side chain. ${ }^{142}$ Furthermore, strong collaborative effect and compatibility between CRP and CuAAC polymerization was observed for improving the controllability (Scheme 8). 


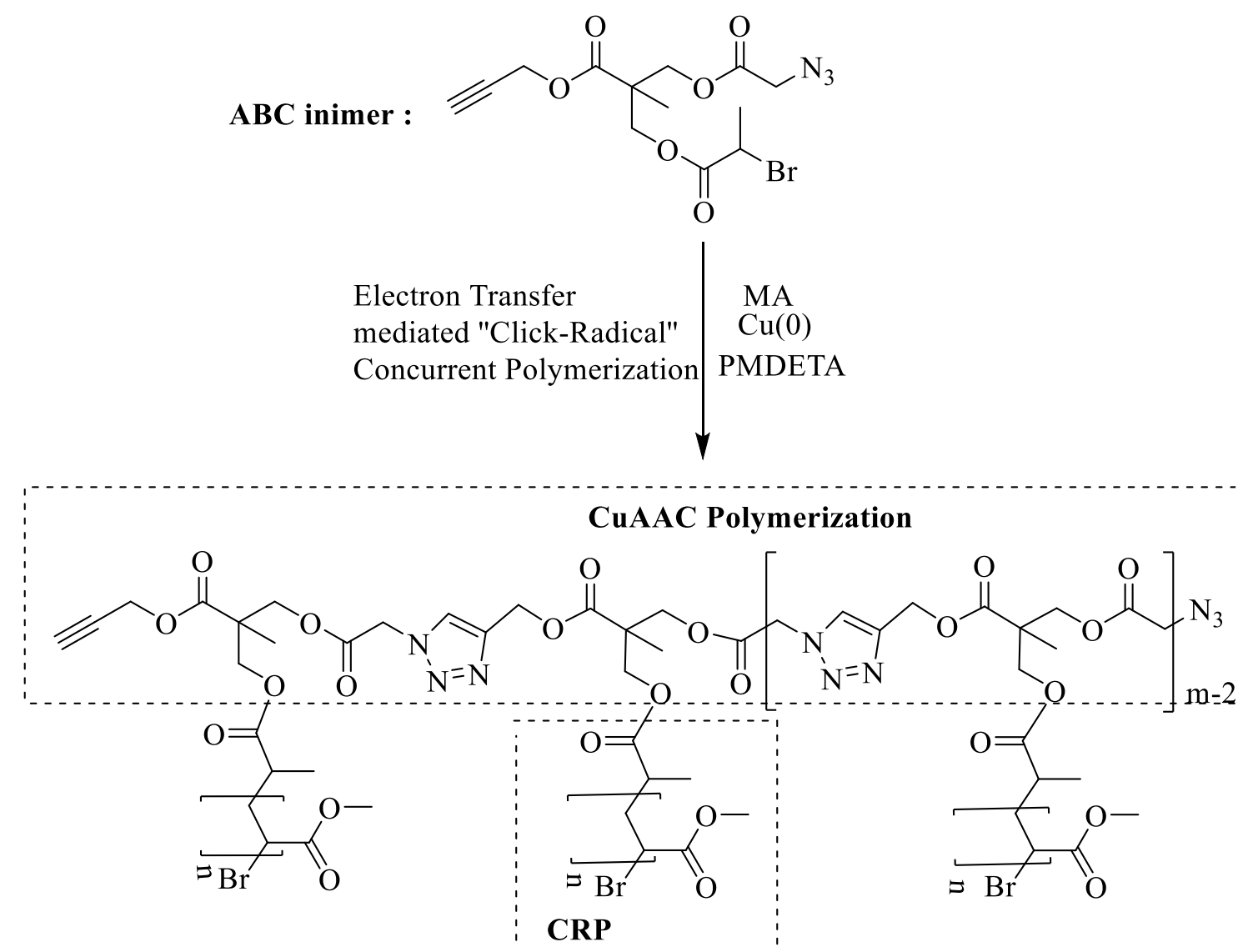

Scheme 8. One-step synthesis of brush polymer from small molecules by concurrent ATRP and coppercatalyzed azide-alkyne cycloaddition (CuAAC) click polymerization

Click reaction has also been explored for the synthesis of $\pi$-conjugated polymers for organic electronics including CuAAC and without CuAAC, featuring essential 'CLICK'" attributes. The alkynebased click polymerizations, derived from click reactions, have attracted much attention because of their advantageous characteristics such as good functional group tolerance, mild reaction conditions, atom economy, high regio- and stereo-selectivity and high yields. ${ }^{143-148}$ Recently, thiol-yne click polymerizations have become significant synthetic tools for the preparation of linear as well as hyperbranched polysulfides with diverse structure and properties. The alkyne monomers used in majority of thiol-yne polymerizations are mainly terminal alkynes while internal alkynes are rarely employed because of their relatively low reactivity.

Jun Du and co-workers developed a catalyst-free click polymerization of activated internal alkynes and thiol. ${ }^{149}$ The polymerization reactions between thiol $\mathbf{1 6}$ and electron deficient internal alkynes (17 and 18) proceeded smoothly in DMF to furnish soluble poly( $\beta$-thioacrylate)s (PTAs) with high molecular weights and Z-stereoregularities in high yields. 
Amna and Ozturk, Org. Commun. (2021) 14:2 97-120<smiles>Sc1ccc(Sc2ccc(S)cc2)cc1</smiles><smiles>[R]C#CC(=O)O[Al]OC(=O)C#C[R]</smiles><smiles>[R]=[V]c1ccccc1</smiles><smiles>CC(=CC(=O)OC(=O)CC(C)(C)C)Sc1ccc(Sc2ccc(SC(C)(C)C)cc2)cc1</smiles><smiles>Cc1ccc(C(=O)c2ccc(Cc3ccc(C(=C(c4ccccc4)c4ccc(C)cc4)c4ccccc4)cc3)cc2)cc1</smiles>

Scheme 9. Synthesis of P1/17a-c and P1/18a-c by catalyst free click polymerization of thiol 16 with internal diynes $\mathbf{1 7}$ and $\mathbf{1 8}$

Hyperbranched polymers is an emerging class of functional polymeric materials, which has gained increasing attention and has found widespread use in the areas of nanomaterials, adhesives, coatings, additives, biomaterials, drug delivery carriers, etc. because of their fascinating attributes, such as excellent solubility, low intrinsic viscosities, interior cavities and abundant surface functional groups. ${ }^{150-157}$ Various polymerization methods such as condensation polymerization, ring-opening polymerization, selfcondensing vinyl polymerization, proton transfer polymerization and addition polymerization have been used for the construction of multifunctional hyperbranched polymers. ${ }^{158-165}$ However, most of these polymerizations require harsh conditions, which complicate the experimental operation and greatly limit their applications. Click polymerization has become a powerful tool for the preparation of functional polymers due to their distinct features of high efficiency, high selectivity, atom economy and mild reaction conditions. At present, functional hyperbranched polymers have been prepared via thiol-ene click polymerization, $\mathrm{Cu}(\mathrm{I})$ - and $\mathrm{Ru}(\mathrm{II})$-catalyzed azide-alkyne click polymerizations, metal-free azide-alkyne click polymerizations and thiol-yne click polymerizations. Recently, another powerful click polymerization, i.e., amino-yne click polymerization, has been developed. ${ }^{166-168}$ This click polymerization protocol belongs to the hydroamination reaction, which is a direct and efficient way for the synthesis of nitrogen containing functional materials. This polymerization can take place at room temperature without the need of any external catalyst, and poly( $\beta$-aminoacrylate)s (PAAs) with high molecular weights could be obtained in high yields. More importantly, this click polymerization can proceed in a regio- and stereospecific fashion, and $100 \%$ E-isomers are afforded in an anti-Markovnikov addition manner.

Benzhao $\mathrm{He}$ and co-workers synthesized a series of multifunctional hyperbranched poly $(\beta-$ aminoacrylate)s (hb-PAAs) via spontaneous amino-yne click polymerization by employing ester activated triyne 19 and diamines 20a-d as monomers. ${ }^{169}$ Various soluble and thermally stable hb-PAAs with high weight-average molecular weights $\left(\mathrm{M}_{\mathrm{w}}\right.$, up to 18,290$)$ were afforded in high yields (up to $99 \%$ ) under mild reaction conditions. Furthermore, by introducing the aggregation-induced emission (AIE)-active tetraphenylethene (TPE) moiety into the backbones, the resultant polymers also displayed a unique AIE feature, and their nanoaggregates could be used for the detection of explosives. The special threedimensional topologies of hyperbranched polymers could effectively improve their detection sensitivity (Scheme 10). 
Click chemistry

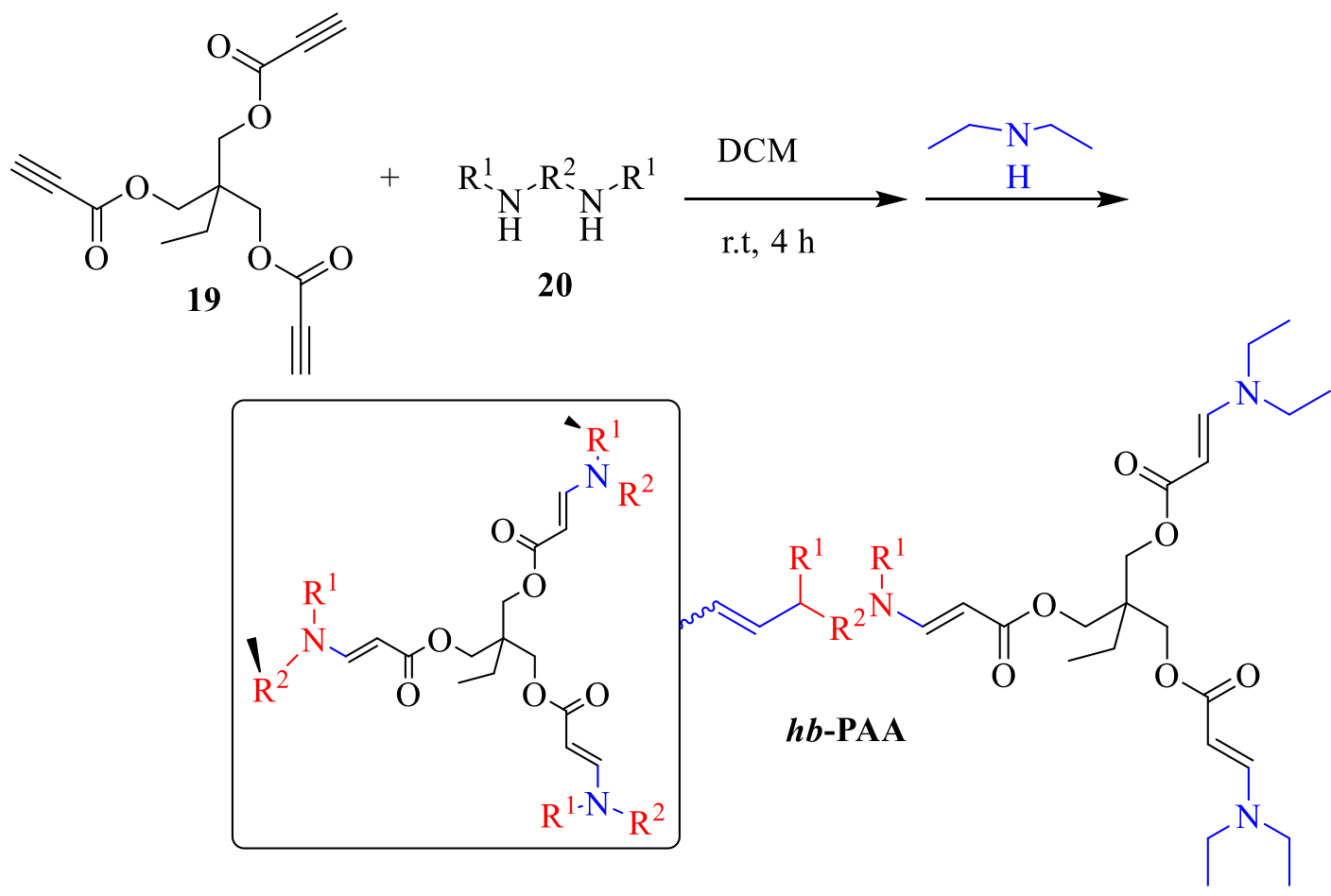<smiles>CCNCCNCCC(C)CNCCC(C)(C)NCC(C)C</smiles><smiles>CNCCCCCOc1ccc(C(=C(c2ccccc2)c2ccc(OCCCCNC)cc2)c2ccccc2)cc1</smiles>

Scheme 10. Syntheses of hyperbranched poly( $\beta$-aminoacrylate)s by spontaneous amino-yne click polymerization

Graft polymers contain complex architecture with multiple polymeric side chains. The synthesis of graft copolymers has an advantage of incorporating properties of two or more polymers that are functionally distinct from their linear copolymer relatives. Conjugated organic polymers are both interesting and feasible to study from a complex architecture viewpoint. Studying complex all-conjugated polymers is advantageous for observing the effect of introducing multidimensional architectures on their optoelectronic properties. Moreover, the overall increased rigidity of conjugated polymers as compared to the nonconjugated polymers is hypothesized to affect the material properties of the resulting graft copolymers.

Nimrat K. Obhi and co-workers used the copper-catalyzed azide-alkyne click (CuAAC) reaction as the grafting-to reaction. ${ }^{170} \mathrm{~A}$ library of well-defined polythiophene backbones and polyselenophene side chains with click-active azide and acetylene functional groups was synthesized using Kumada catalyst transfer polymerization (KCTP). Control test reactions displayed excellent azide group tolerance to CuAAC click conditions, and successful synthesis of a $100 \%$ graft copolymer using a polythiophene 
Amna and Ozturk, Org. Commun. (2021) 14:2 97-120

backbone and small molecule 4-ethynyl- $\alpha, \alpha, \alpha$-trifluorotoluene (ETFT) was also performed under these conditions.

Click chemistry reaction conditions were assessed by performing two test reactions. In the first test reaction, it was observed that the CuAAC click conditions did not affect the integrity of the azide groups on the polythiophene backbone, hence, eliminating the possibility of azide crosslinking during the comb reactions. Specifically, a $14.5 \mathrm{kDa}$ polythiophene backbone with $53 \% \mathrm{~N}_{3}$ was treated with the CuAAC click conditions in the absence of any alkyne-functionalized molecules. CuAAC conditions were used which are most commonly employed for polymer-polymer click reactions, involving the use of $\mathrm{Cu}(\mathrm{I}) \mathrm{Br}$ in conjunction with amine ligand PMDETA with the application of heat (Scheme 11). In the second reaction, efficiency of the grafting-to click procedure was assessed by using small molecule alkyne 4ethynyl- $\alpha, \alpha, \alpha$-trifluorotoluene (ETFT) 21. 100\% grafting of ETFT to the $53 \% \mathrm{~N}_{3}$ backbone was obtained using the same CuAAC conditions described for the first reaction. The backbone (B1) was treated with a stoichiometric amount of the small molecule and 1.2 equivalents of $\mathrm{Cu}(\mathrm{I}) \mathrm{Br} / \mathrm{PMDETA}$ relative to the percentage of azide groups. Excellent efficiency of the grafting-to procedure using the $\mathrm{Cu}(\mathrm{I}) \mathrm{Br} / \mathrm{PMDETA}$ click system with a small molecule suggested that this grafting-to procedure could be appropriate for comb copolymer synthesis (Scheme 12).

a)

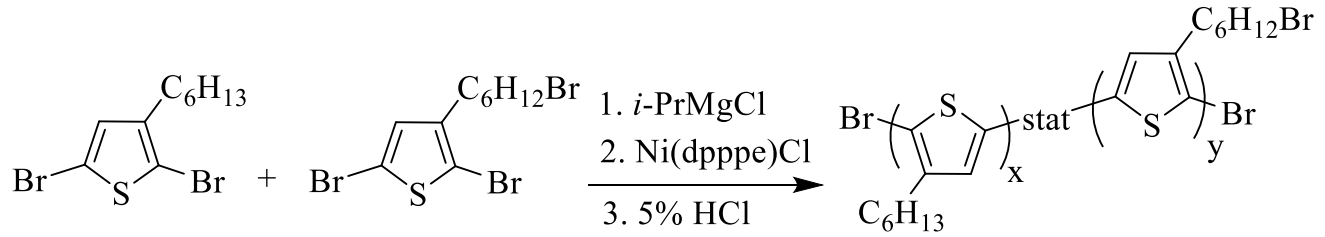

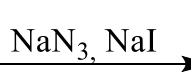

$\mathrm{NaN}_{3}, \mathrm{NaI}$

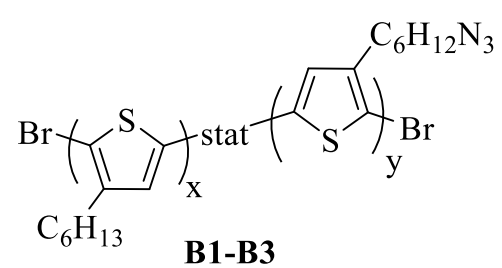

b)
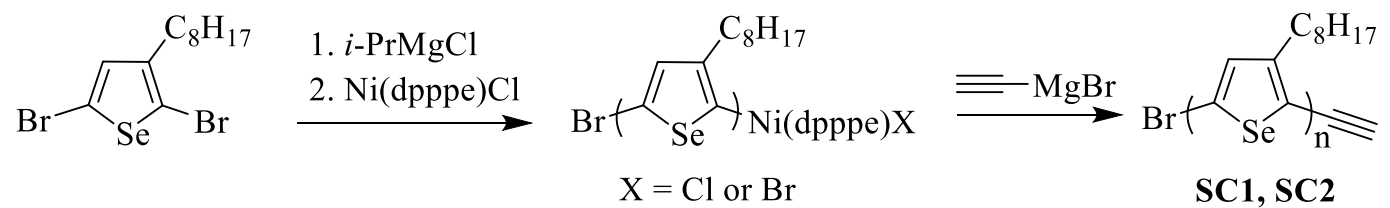

$\mathrm{SC} 1, \mathrm{SC} 2$

$\mathrm{C}_{8} \mathrm{H}_{17}=2$-ethylhexyl

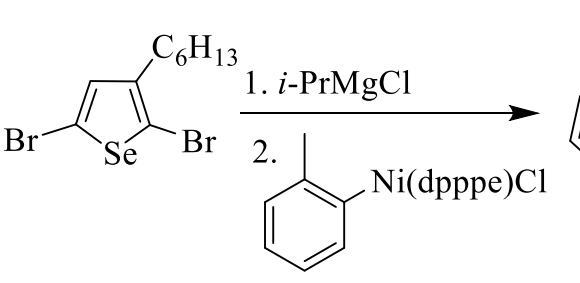

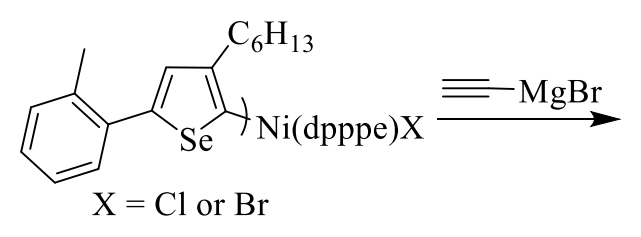<smiles></smiles>

SC3-SC6

Scheme 11. Synthesis of (a) Polythiophene backbone copolymers and (b) Polyselenophene side chains using Kumada catalyst-transfer polycondensation 


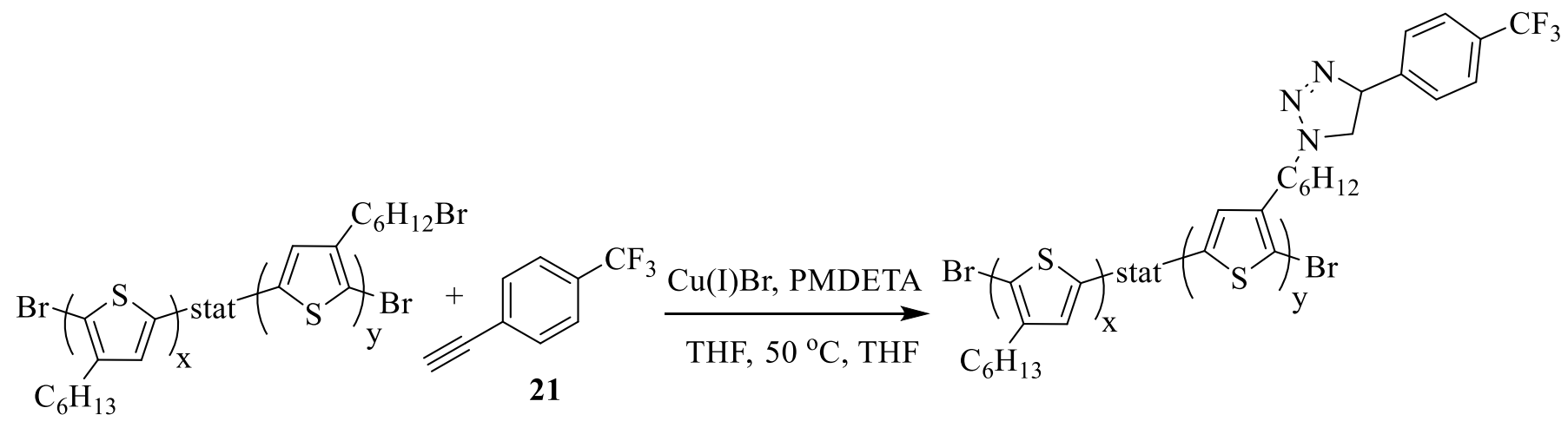

Scheme 12. General scheme for control click reactions using small molecule 4-ethynyl- $\alpha, \alpha, \alpha-$ trifluorotoluene 21

\section{Drug Delivery}

$\mathrm{CC}$ is of tremendous help to meet the demand of modern-day chemistry research, mainly drug discovery. It uses pairs of functional groups that rapidly and selectively react (click reaction) with each other in ecofriendly, mild, aqueous conditions as well as in organic solvents. The selection of each click reaction is based on its selectivity, reactivity, biocompatibility, and stability. Click chemistry has greatly facilitated the overall drug discovery process by providing easy access to the synthesis of building blocks for new molecular entities (NMEs). Although it has by no means replaced existing methods for drug discovery, it has complemented and extended them by aiding lead discovery and optimization. ${ }^{171}$

Nanosystems that release cancer drugs in response to an external stimulus offers unique advantages over commonly used conventional carriers that release their payload in a passive fashion. Reduced graphene oxide $(\mathrm{rGO})$ nanosheets with restored $\mathrm{sp}^{2}$ network have been shown to be ideally suited for drug loading and release based applications. ${ }^{172-180}$ Since effective functionalization of the rGO through covalent transformations is limited, the non-covalent $\pi-\pi$ stacking based functionalization route of rGO scaffold has been extensively explored. ${ }^{181-186}$ On the other hand, this strategy was found to be effective for the molecules which are able to form efficient non-covalent interactions. Conjugation of molecules unable to undergo such associations with rGO is quite challenging. For the functionalization of rGO, aromatic anchoring groups such as tetrathiafulvalene (TTF), ${ }^{183,185}$ pyrene $^{181,187}$ and dopamine derivatives ${ }^{184,186}$ are of great significance. Dopamine containing clickable azide and alkyne groups have also been used for the functionalization of rGO. ${ }^{184,186}$ The azide containing $\mathrm{rGO}$ could be further modified with alkynylterminated molecules such as ferrocene using $\mathrm{Cu}(\mathrm{I})$ catalyzed azide-alkyne Huisgen-type click reaction. The azide-alkyne based functionalization of rGO was effective but using copper as a catalyst could be of concern for biomedical applications as the cytotoxicity of nanostructures could be enhanced by any trace of copper. This necessitates to develop click reactions that do not require metal catalysts such as nucleophilic or radical thiol-ene reactions and strain-promoted azide-alkyne cycloaddition (SPAAC). ${ }^{188}$ Nucleophilic thiol-ene based reactions using the thiolmaleimide functional group dyad has been extensively utilized in bio-conjugations. The maleimide-thiol addition reaction is an efficient protocol that could be used under mild reaction conditions without using any catalyst.

Yavuz $\mathrm{Oz}$ and co-workers investigated the maleimide-containing catechol (dopa-MAL) ligand as a versatile surface anchor onto reduced graphene oxide ( $\mathrm{rGO}$ ) nanosheets. ${ }^{189}$ Thiol-maleimide chemistry allowed facile attachment of thiol-containing molecules under ambient metal-free conditions. While the attachment of glutathione and 6-(ferrocenyl)hexanethiol was used as models, the attachment of a cancer cell targeting cyclic peptide, c(RGDfC), opened the possibility of using the dopa-MAL modified rGO as a targeted drug delivery system for doxorubicin (DOX). This approach was shown to be effective not only for model molecules such as glutathione and ferrocene containing a thiol group, but it was also adaptable to the covalent linking of thiol containing tripeptides, such as the cancer cell targeting peptide c(RGDfC). The facile fabrication and functionalization to readily obtain a functional material in a modular fashion make this clickable-rGO construct an attractive candidate for various useful applications. 
Amna and Ozturk, Org. Commun. (2021) 14:2 97-120

A metal-free "click" conjugation protocol using strain-promoted click chemistry was explored as a facile and fast tool for the functionalization of microbubbles with drug encapsulated nanoparticles, siRNA encapsulated micelles and protein molecules. ${ }^{190}$ This microbubble-therapeutic "click" conjugation established in the current study did not require any catalyst or initiator, did not involve toxic agents, had ultra-fast reaction speed, and was versatile for the ligation of different anticancer or therapeutic agents to the microbubbles. These advantages made it a favorable protocol for use in various biomedical research and clinical applications such as therapeutic delivery for inflammation, tumor treatment, thrombosis and angiogenesis in different organs and real-time imaging.

The combination of copper-free click chemistry with metabolic labeling have opened new avenues in drug delivery. Nicolas Alcaraz and co-workers conducted a study to determine whether cubosomes functionalized with azide or dibenzocyclooctyne (DBCO) groups were able to undergo copper-free click chemistry with a strained cyclooctyne or azide, respectively. ${ }^{191}$ Phytantriol-based cubosomes were functionalized by phospholipids containing an azide or DBCO group. The efficiency of "clickability" was estimated by the reaction of cubosomes with a complementary dye and determining bound and unbound dye through size exclusion chromatography. The clickable cubosomes reacted specifically with a clickCy5 dye with minor changes to the shape, size and structure of the cubosomes. This showed that cubosomes could retain their unique internal structure while participating in copper-free click chemistry. This proof of concept study could pave the way for the utilization of copper-free click chemistry and metabolic labeling with cubosomes for targeted drug delivery and imaging.

In the past few years, Smart hydrogels have become an attractive candidate in biomaterials fields for promising applications in drug delivery and tissue engineering. ${ }^{192-197}$ Hydrogels can change their permeability, volume and phase state in response to the external stimuli such as $\mathrm{pH},{ }^{198}$ temperature, ${ }^{199}$ UV-light, ${ }^{200}$ enzymes, ${ }^{201}$ electric or magnetic fields ${ }^{202}$ and/or oxidizing or reducing agents. ${ }^{203}$ For biological applications, $\mathrm{pH} /$ temperature responsive hydrogels are considered more useful because temperature and $\mathrm{pH}$ are the most affected environmental stimuli under in vitro and in vivo conditions. ${ }^{204}$ Thiol-ene chick chemistry offers many advantages for hydrogel formation, such as insensitivity to oxygen and rapid stoichiometrically controlled polymerization via photoinitiation. ${ }^{205,206}$ Stimuli-responsive chitosan (CS) hydrogels displayed a great potential for drug delivery and tissue engineering; however, the structure of these stimuliresponsive CS hydrogels, such as dual $\mathrm{pH}$ - and thermo-responsive hydrogels, is difficult to control or needs additional crosslinking agents.

Haichang Ding and co-workers reported a novel dual $\mathrm{pH}$ - and thermo-responsive hydrogel system by combining $\mathrm{pH}$-responsive $\mathrm{C}_{6}-\mathrm{OH}$ allyl-modified $\mathrm{CS}$ (OAL-CS) with thermo-responsive poly $(\mathrm{N}$ isopropylacrylamide) (PNIPAM) ${ }^{207}$ The thiol groups in PNIPAM and the allyl groups in OAL-CS could rapidly form crosslinking hydrogel network by "thiol-ene" click chemistry under UV irradiation. The swelling ratio of the OAL-CS/PNIPAM hydrogel could be controlled by changing temperature and $\mathrm{pH}$. Furthermore, the hydrogel displayed non-cytotoxic nature toward human bone marrow mesenchymal stem cells, and the histological analyses revealed the subcutaneous tissue with no signs of inflammation after five days of injection in vivo. The results showed that the new OAL-CS/PNIPAM hydrogel had potential to serve as a smart injectable platform to be utilized in drug delivery and tissue engineering.

Clara García-Astrain and co-workers reported a series of chemically cross-linked alginate hydrogels, synthesized through click chemistry via Diels-Alder reaction by reacting furan-modified alginate and bifunctional cross-linkers. ${ }^{208}$ Furfurylamine was used for the functionalization of alignate. Then, 3D architectures were synthesized with water-soluble bismaleimides. Different substitution degrees were obtained for investigating the effect of alginate modification and the cross-linking extent over the behavior of the hydrogels. The ensuing hydrogels were analyzed in terms of swelling, microstructure, rheological behavior and structure modification. The materials response to external stimuli such as $\mathrm{pH}$ was also studied, revealing a pulsatile behavior in a large $\mathrm{pH}$ range (1-13) and a clear $\mathrm{pH}$-dependent swelling. Finally, vanillin release studies were conducted in order to display the potential of these biobased materials for drug delivery applications.

\section{Conclusion}


Click chemistry has become one of the most powerful strategies in materials and biomedical sciences due to the efficiency, selectivity and tolerance of this class of reactions to a variety of solvents and functional groups. By far the most widely utilized of these efficient transformation reactions is the CuI-catalyzed azide-alkyne cycloaddition. This reaction has been creatively employed to facilitate the preparation of versatile molecules to be employed in different areas of chemistry including bioconjugation, drug delivery and polymer chemistry. Click chemistry has enabled the researchers to explore complex materials while simplifying their preparation methods. Additional reactions that can provide the benefits of click chemistry have been increasingly investigated, which are helpful in expanding the range of available functional groups that can participate in highly efficient chemical transformations. Overall, the results from research to date suggest that click chemistry has emerged as a valuable tool in biomedical fields as well as in material chemistry.

\section{Acknowledgements}

One of the authors, Bibi Amna, is grateful to TÜBITAK 2216 research fellowship program for international researchers, for granting her fellowship.

\section{ORCID}

Bibi Amna : 0000-0003-1581-7091

Turan Ozturk: 0000-0003-3777-5320

\section{References}

[1] 217th American Chemical Society annual meeting, 1999.

[2] Kolb, H.C.; Finn, M. G.; Sharpless, K.B. Click chemistry: diverse chemical function from a few good reactions. Angew. Chem. Int. Ed. 2001, 40, $2004-2021$.

[3] Gontcharov, A.V. tert-Butylsulfonamide. A new nitrogen source for catalytic aminohydroxylation and aziridination of olefins. Org. Lett. 1999, 1, 783-786

[4] Kolb, H.C. Catalytic asymmetric dihydroxylation. Chem. Rev. 1994, 94, 2483-2547.

[5] Adolfsson, H. Comparison of amine additives most effective in the new methyltrioxorhenium-catalyzed epoxidation process. Tetrahedron Lett. 1999, 40, 3991-3994.

[6] Kühle, E. One-hundred years of sulfenic acid chemistry. IIa. Oxidation, reduction, and addition reactions of sulfenyl halides. Synthesis (Mass.) 1970, 11, 563-586

[7] Huisgen, R.,1,3-Dipolar cycloaddition - introduction, survey, mechanism. In 1,3-Dipolar Cycloaddition, Padwa, A.; Eds; John Wiley and Sons, New York, 1984.

[8] Jorgensen, K.A. Catalytic asymmetric hetero-Diels-Alder reactions of carbonyl compounds and imines. Angew. Chem. Int. Ed. Engl. 2000, 39, 3558-3588

[9] Tietze, L.F.; Kettschau, G., Hetero Diels-Alder reactions in organic chemistry. Top. Curr. Chem. 1997, 189, $1-120$

[10] Rostovtsev, V. V.; Green, L. G.; Fokin, V. V.; Sharpless, K. B. A stepwise Huisgen cycloaddition process: copper(I)-catalyzed regioselective "ligation" of azides and terminal alkynes. Angew. Chem., Int. Ed. 2002, 41, 2596-2599.

[11] Tornøe, C. W.; Christensen, C.; Meldal, M. Peptidotriazoles on solid phase:[1, 2, 3]-triazoles by regiospecific copper (I)-catalyzed 1,3-dipolar cycloadditions of terminal alkynes to azides. J. Org. Chem. 2002, 67, 30573064.

[12] Binder, W. H.; Sachsenhofer, R. Click chemistry in polymer and material science: an update. Macromol. Rapid Commun. 2008, 29, 952-981.

[13] Breinbauer, R.; Kohn, M. Azide-alkyne coupling: a powerful reaction for bioconjugate chemistry. ChemBioChem. 2003, 4, 1147-1149.

[14] Kolb, H.C.; Sharpless, K. B. Drug discovery today, the growing impact of click chemistry on drug discovery. Drug Discov. Today 2003, 8, 1128-1137.

[15] Gholami, M. R; Yangjeh, A.H. Hydrophobic effects in 1,3- dipolar cycloaddition of C,N-diphenylnitrone with Dibutyl fumarate in aqueous solutions. J. Chem. Res. 1999, 3, 226-227

[16] Lee, L.V.; Mitchell, M.L.; Huang, S.J.; Valery V. Fokin, V.V.; Sharpless, K.B.; Wong, C.H. A potent and highly selective inhibitor of human a-1,3-Fucosyltransferase via click chemistry. J. Am. Chem. Soc. 2003, $125,9588-9589$ 
Amna and Ozturk, Org. Commun. (2021) 14:2 97-120

[17] Moses, J.E.; Moorhouse, A.D. The growing applications of click chemistry. Chem. Soc. Rev., 2007, 36, $1249-1262$.

[18] Hang, H. C.; Bertozzi, C. R. Chemoselective approaches to glycoprotein assembly, Acc. Chem. Res. 2001, $34,727-736$.

[19] Saxon, E.; Bertozzi, C. R. Cell surface engineering by a modified Staudinger reaction. Science 2000, 287, 2007-2010

[20] Kiick, K. L.; Saxon, E.; Tirrell, D. A.; Bertozzi, C. R. Incorporation of azides into recombinant proteins for chemoselective modification by the Staudinger ligation. Proc. Natl. Acad. Sci. USA 2002, 99, 19 -24.

[21] Breinbauer, R.; Kohn, M. Azide-alkyne coupling: a powerful reaction for bioconjugate chemistry. ChemBioChem. 2003, 4, 1147-1149.

[22] Lewis, W. G.; Green, L. G.; Grynszpan, F.; Radic, Z.; Carlier, P. R.; Taylor, P.; Finn, M. G.; Sharpless, K. B. Click chemistry in situ: acetylcholinesterase as a reaction vessel for the selective assembly of a femtomolar inhibitor from an array of building blocks. Angew. Chem. 2002, 114, $1095-1098$.

[23] Tornoe, C. W.; Christensen, C.; Meldal, M. Peptidotriazoles on solid phase:[1, 2, 3]-triazoles by regiospecific copper (I)-catalyzed 1, 3-dipolar cycloadditions of terminal alkynes to azides. J. Org. Chem. 2002, 67, 3057 - 3064.

[24] Fazio, F.; Bryan, M. C.; Blixt, O.; Paulson, J. C.; Wong, C. H. Synthesis of sugar arrays in microtiter plate. J. Am. Chem. Soc. 2002, 124, 14397-14402.

[25] Perez-Balderas, F.; Munoz, M.O.; Sanfrutos, J.M.; Mateo, F.H.; Flores, F.C.C.; Asin, J. A. C.; Garcia, J. I.; Gonzalez, F. A. G. Multivalent neoglycoconjugates by regiospecific cycloaddition of alkynes and azides using organic-soluble copper catalysts. Org. Lett. 2003, 5, 1951-1954.

[26] Liu, Y.; Hou, W.; Sun, H.; Cui, C.; Zhang, L.; Jiang,Y.; Wu,Y.X.; Wang, Y.; Li, J.; Sumerlin, B.S.; Liu. Q.; Tan, W. Thiol-ene click chemistry: a biocompatible way for orthogonal bioconjugation of colloidal nanoparticles. Chem. Sci. 2017, 8, 6182-6187.

[27] Ramachandra, L.; Simmons, D.; Harding, C. V. MHC molecules and microbial antigen processing in phagosomes. Curr. Opin. Immunol. 2009, 21, 98-104.

[28] Burgdorf, S.; Kurts, C. Endocytosis mechanisms and the cell biology of antigen presentation. Curr. Opin. Immunol. 2008, 20, 89-95.

[29] Yoshida, T.; Mei, H.; Doerner, T.; Hiepe, F.; Radbruch, A.; Fillatreau, S.; Hoyer, B. F. Memory B and memory plasma cells. Immunol. Rev. 2010, 237, 117-139.

[30] Bachmann, M. F., and Jennings, G. T., Vaccine delivery: a matter of size, geometry, kinetics and molecular patterns. Nat. Rev.Immunol. 2010, 10, 787-96.

[31] Costantino, P.; Rappuoli, R.; Berti, F. The design of semi-synthetic and synthetic glycoconjugate vaccines. Expert Opin. Drug Discov. 2011, 6, 1045-1066.

[32] Yin, Z.; Comellas-Aragonés, M.; Chowdhury, S.; Bentley, P.; Kaczanowska, K.; Benmohamed, L.; Gildersleeve, J. C.; Finn, M. G.; Huang, X. Boosting immunity to small tumor associated carbohydrates with bacteriophage qbeta capsids. ACS Chem. Biol. 2013, 8, 1253-1262.

[33] Ceballos-Alcantarilla, E.; Abad-Somovilla, A.; Agulló, C.; Abad-Fuentes, A.; Mercader, J. V. Protein-free hapten-carbon nanotube constructs induce the secondary immune response. Bioconjugate Chem. 2017, 28, 1630-1638.

[34] Parra, J.; Abad-Somovilla, A.; Mercader, J. V.; Taton, T. A.; Abad-Fuentes, A. Carbon nanotube-protein carriers enhance size-dependent self-adjuvant antibody response to haptens. J. Controlled Release 2013, 170, 242-251.

[35] Pickens, C. J.; Johnson, S. N.; Pressnall, M. M.; Leon, M. A.; Berkland, C. J. Practical considerations, challenges, and limitations of bioconjugation via azide-alkyne cycloaddition. Bioconjugate Chem. 2018, 29, 686-701.

[36] Elahipanah, S.; O’Brien, P. J.; Rogozhnikov, D.; Yousaf, M.N. General dialdehyde click chemistry for amine bioconjugation. Bioconjugate Chem. 2017, 28, 1422-1433.

[37] López-Puertollano,D.; Agulló,C.; Mercader, J.V.; Abad-Somovilla, A.; Abad-Fuentes, A. Click chemistryassisted bioconjugates for hapten immunodiagnostics. Bioconjugate Chem. 2020, 31, 956-964.

[38] Stephanopoulos, N.; Francis, M. B. Choosing an effective protein bioconjugation strategy. Nat. Chem. Biol. 2011, 7, 876-884.

[39] Zhou, Q.; Gui, J.; Pan, C.M.; Albone, E.; Cheng, X.; Suh, E. M.; Grasso, L.; Ishihara, Y.; Baran, P. S. Bioconjugation by native chemical tagging of C-H bonds. J. Am. Chem. Soc. 2013, 135, 12994-12997.

[40] Smith, M. E. B.; Schumacher, F. F.; Ryan, C. P.; Tedaldi, L. M.; Papaioannou, D.; Waksman, G.; Caddick, S.; Baker, J. R. Protein modification, bioconjugation, and disulfide bridging using bromomaleimides. J. Am. Chem. Soc. 2010, 132, 1960-1965.

[41] Debets, M. F.; van Berkel, S. S.; Dommerholt, J.; Dirks, A. J.; Rutjes, F. P. J. T.; Delft, F. L.V. Bioconjugation with strained alkenes and alkynes. Acc. Chem. Res. 2011, 44, 805-815. 
[42] Hecht, S.; Fréchet, J. M. J. Dendritic encapsulation of function: applying nature's site isolation principle from biomimetics to materials science. Angew. Chem., Int. Ed. 2001, 40, 74-91.

[43] Mckittrick, M. W.; Jones, C. W. Toward single-site functional materials preparation of amine-functionalized surfaces exhibiting site-isolated behavior. Chem. Mater. 2003, 15, 1132-1139.

[44] Ferruti, P.; Marchisio, M. A.; Duncan, R. Poly(amido-amine)s: biomedical applications. Macromol. Rapid Commun. 2002, 23, 332-355.

[45] Paetzold, J.; Baeckvall, J. E. Chemoenzymatic dynamic kinetic resolution of primary amines. J. Am. Chem. Soc. 2005, 127,17620-17621.

[46] Binder, W. H.; Sachsenhofer, R. 'Click' chemistry in polymer and material science: an update. Macromol. Rapid Commun. 2008, 29, 952-981.

[47] Elahipanah, S.; O’Brien, P.J.; Rogozhnikov, D.; Yousaf,M.N. General Dialdehyde Click Chemistry for Amine Bioconjugation. Bioconjugate Chem. 2017, 28, 1422-1433.

[48] Durmaz, H.; Dag, A.; Altintas, O.; Erdogan, T.; Hizal, G.; Tunca, U. One-pot synthesis of ABC type triblock copolymers via in situ click [3+2] and Diels- Alder [4+2] reactions. Macromolecules 2007, 40, 191-198.

[49] Opsteen, J. A.; van Hest, J. C. M. Modular synthesis of block copolymers via cycloaddition of terminal azide and alkyne functionalized polymers. Chem. Commun. 2005, 57-59.

[50] Kyeremateng, S. O.; Amado, E.; Blume, A.; Kressler, J. Synthesis of ABC and CABAC triphilic block copolymers by ATRP combined with 'click' chemistry, Macromol. Rapid Commun. 2008, 29, 1140-1146.

[51] Quemener, D.; Davis, T. P.; Barner-Kowollik. C.; Stenzel, M. H. RAFT and click chemistry: A versatile approach to well-defined block copolymers. Chem. Commun. 2006, 5051-5053.

[52] O'Reilly, R. K.; Joralemon, M. J.; Wooley. K. L.; Hawker, C. J. Functionalization of Micelles and Shell Cross-linked Nanoparticles Using Click Chemistry. Chem. Mater. 2005, 17, 5976-5988.

[53] Joralemon, M. J.; O’Reilly, R. K.; Hawker, C. J.; Wooley, K. L. Shell click-crosslinked (SCC) nanoparticles: a new methodology for synthesis and orthogonal functionalization. J. Am. Chem. Soc. 2005, 127, 16892 16899.

[54] Opsteen, J. A.; Brinkhuis, R. P.; Teeuwen, R. L. M.; Loewik, D. W. P. M.; van Hest, J. C. M. "Clickable" polymersomes, Chem. Commun. 2007, 3136-3138.

[55] Levins, A. D.; Wang, X.; Moughton, A. O.; Skey. J.; O’Reilly, R. K. Synthesis of core functionalized polymer micelles and shell cross-linked nanoparticles, Macromolecules 2008, 41, 2998-3006.

[56] Jiang, X.; Zhang, G.; Narain.R.; Liu, S. Fabrication of two types of shell-cross-linked micelles with "inverted" structures in aqueous solution from schizophrenic water-soluble $\mathrm{ABC}$ triblock copolymer via click chemistry. Langmuir 2009, 25, 2046-2054.

[57] Sumerlin, B. S.; Tsarevsky, N. V.; Louche,G.; Lee, R. Y.; Matyjaszewski, K. Highly efficient "click" functionalization of poly (3-azidopropyl methacrylate) prepared by ATRP. Macromolecules 2005, 38, 75407545.

[58] Chan, T. R.; Hilgraf, R.; Sharpless, K.B.; Fokin, V. V. Polytriazoles as copper (I)-stabilizing ligands in catalysis. Org. Lett. 2004, 6, 2853-2855.

[59] Ladmiral, V.; Mantovani, G.; Clarkson, G. J.; Cauet, S.; Irwin, J. L.; Haddleton, D. M. Synthesis of neoglycopolymers by a combination of "click chemistry" and living radical polymerization. J. Am. Chem. Soc. 2006, $128,4823-4830$.

[60] Binder, W. H.; Kluger, C. Combining ring-opening metathesis polymerization (ROMP) with Sharpless-type "click" reactions: An easy method for the preparation of side chain functionalized poly(oxynorbornenes). Macromolecules 2004, 37, 9321-9330.

[61] Malkoch, M.; Thibault, R. J.; Drockenmuller, E.; Messerschmidt, M.; Voit,B.; Russell, T. P., Hawker, C. J. Orthogonal approaches to the simultaneous and cascade functionalization of macromolecules using click chemistry. J. Am. Chem. Soc. 2005,127, 14942-14949.

[62] Crescenzi, V.; Cornelio, L.; Di Meo,C.; Nardecchia, S.; Lamanna, R. Novel hydrogels via click chemistry: synthesis and potential biomedical applications, Biomacromolecules 2007, 8, 1844-1850.

[63] Matsumura,G.; Pigman, W. Catalytic role of copper and iron ions in the depolymerization of hyaluronic acid by ascorbic acidArch. Biochem. Biophys. 1965, 110, 526-533

[64] Xia, Y.; Verduzco, R.; Grubbs, R. H.; Kornfield, J. A. Well-defined liquid crystal gels from telechelic polymers. J. Am.Chem. Soc. 2008, 130, 1735-1740.

[65] Johnson, J. A.; Lewis, D. R.; Diaz, D. D.; Finn, M. G.; Koberstein, J. T.; Turro, N. J. Synthesis of degradable model networks via ATRP and click chemistry. J. Am. Chem. Soc. 2006, 128, 6564-6565.

[66] Johnson, J. A.; Finn, M. G.; Koberstein, J. T.; Turro, N. J. Construction of linear polymers, dendrimers, networks, and other polymeric architectures by copper-catalyzed azide-alkyne cycloaddition "click" chemistry. Macromol. Rapid Commun. 2008, 29,1052-1072.

[67] Li, Y.; Zheng, X.; Zhu, H.; Wu, K.; Lu, M. Synthesis and self-assembly of well-defined binary graft copolymer and its use in superhydrophobic cotton fabrics preparation. RSC Adv. 2015, 5, 46132-46145. 
Amna and Ozturk, Org. Commun. (2021) 14:2 97-120

[68] Smith, K. A.; Lin, Y. H.; Dement, D. B.; Strzalka, J.; Darling, S.B.; Pickel, D. L.; Verduzco, R. Synthesis and crystallinity of conjugated block copolymers prepared by click chemistry. Macromolecules 2013, 46, 2636-2645.

[69] Arslan, M.; Gok, O.; Sanyal, R.; Sanyal, A. Clickable poly(ethylene glycol)-based copolymers using azidealkyne click cycloaddition-mediated step-growth polymerization. Macromol. Chem. Phys. 2014, 215, 2237-2247.

[70] Johansson, J. R.; Beke-Somfai, T.; Said Stålsmeden, A.; Kann, N. Ruthenium-catalyzed azide alkyne cycloaddition reaction: scope, mechanism, and applications. Chem. Rev. 2016, 116, 14726-14768.

[71] Li, L.; Hollinger, J.; Jahnke, A. A.; Petrov, S.; Seferos, D. S. Polyselenophenes with distinct crystallization properties. Chem. Sci. 2011, 2, 2306-2310.

[72] Hollinger, J.; Jahnke, A. A.; Coombs, N.; Seferos, D. S. Controlling phase separation and optical properties in conjugated polymers through selenophene-thiophene copolymerization. J. Am. Chem. Soc. 2010, 132, $8546-8547$.

[73] Gao, D.; Hollinger, J.; Seferos, D. S. Selenophene-thiophene block copolymer solar cells with thermostable nanostructures. ACS Nano, 2012, 6, 7114-7121.

[74] Hollinger, J.; Seferos, D. S. Morphology control of selenophene-thiophene block copolymers through side chain engineering. Macromolecules 2014, 47, 5002-5009.

[75] Gao, D.; Hollinger, J.; Jahnke, A. A.; Seferos, D. S. Influence of selenophene-thiophene phase separation on solar cell performance. J. Mater. Chem. A 2014, 2, 6058-6063.

[76] Hollinger, J.; Sun, J.; Gao, D.; Karl, D.; Seferos, D. S. Statistical conjugated polymers comprising optoelectronically distinct units. Macromol. Rapid Commun. 2013, 34, 437-441.

[77] Kozycz, L. M.; Gao, D.; Seferos, D. S. Compositional Influence on the regioregularity and device parameters of a conjugated statistical copolymer. Macromolecules 2013, 46, 613-621.

[78] Gao, H.; Matyjaszewski, K. Synthesis of star polymers by a combination of ATRP and the "click" coupling method. Macromolecules 2006, 39,4960-4965.

[79] Gao, H.; Min K.; Matyjaszewski, K. Synthesis of 3-arm star block copolymers by combination of "core-first" and "coupling-onto" methods using ATRP and click reactions. Macromol. Chem. Phys. 2007, 208, 13701378.

[80] Altintas, O.; Hizal, G.; Tunca, U. ABC-type hetero-arm star terpolymers through “click" chemistry. J. Polym. Sci., Part A: Polym. Chem. 2006, 44, 5699-5707.

[81] Whittaker, M. R.; Urbani, C. N.; Monteiro, M. J. Synthesis of 3-miktoarm stars and 1st generation mikto dendritic copolymers by "living" radical polymerization and "click" chemistry. J. Am. Chem. Soc. 2006, 128, $11360-11361$.

[82] Liu, H.; Li, C.; Liu, H.; Liu, S. pH-responsive supramolecular self-assembly of well-defined zwitterionic ABC miktoarm star terpolymers. Langmuir, 2009, 25, 4724-4734.

[83] Altintas, O.; Hizal, G.; Tunca, U. Synthesis of an ABCD 4-miktoarm star quaterpolymer through a DielsAlder click reaction. Des. Monomers Polym. 2009, 12, 83-98.

[84] Zhang, Y.; Liu, H.; Hu, J.; Li, C.; Liu, S. Synthesis and aggregation behavior of multi-responsive double hydrophilic ABC miktoarm star terpolymer. Macromol. Rapid Commun. 2009, 30, 941-947.

[85] Gao, H.; Matyjaszewski, K. Synthesis of molecular brushes by "grafting onto" method: combination of ATRP and click reactions. J. Am. Chem. Soc. 2007, 129, 6633-6639.

[86] Tsarevsky, N. V.; Bencherif, S. A.; Matyjaszewski, K. Graft copolymers by a combination of ATRP and two different consecutive click reactions. Macromolecules 2007, 40, 4439-4445.

[87] Li, C.; Ge, Z.; Fang, J.; Liu, S. Synthesis and self-assembly of coil-rod double hydrophilic diblock copolymer with dually responsive asymmetric centipede-shaped polymer brush as the rod segment. Macromolecules 2009, 42, 2916-2924.

[88] Scheel, A. J.; Komber, H.; Voit, B. I. Novel hyperbranched poly([1,2,3]triazole)s derived from AB2 monomers by a 1,3-dipolar cycloaddition. Macromol. Rapid Commun. 2004, 25, 1175-1180.

[89] Saha, A.; Ramakrishnan, S. Site-specific functionalization of hyperbranched polymers using "click" chemistry. Macromolecules 2009, 42,4028-4037.

[90] Qin, A.; Lam, J. W. Y.; Jim, C. K. W.; Zhang, L.; Yan, J.; Haussler, M.; Liu, J.; Dong, Y.; Liang, D.; Chen, E.; Jia, G.; Tang, B. Z.Hyperbranched polytriazoles: Click polymerization, regioisomeric structure, light emission, and fluorescent patterning. Macromolecules 2008,41, 3808-3822.

[91] Xie, J.; Hu, L.; Shi, W.; Deng, X.; Cao, Z.; Shen, Q. Synthesis and nonlinear optical properties of hyperbranched polytriazole containing second-order nonlinear optical chromophore. J. Polym. Sci., Part B: Polym. Phys. 2008, 46, 1140-1148.

[92] Li, Z. a.; Yu, G.; Hu, P.; Ye, C.; Liu, Y.; Qin, J.; Li, Z. New azo-chromophore-containing hyperbranched polytriazoles derived from AB2 monomers via click chemistry under copper(I) catalysis. Macromolecules 2009, 42, 1589-1596. 
[93] Ranjan, R.; Brittain, W. J. Tandem RAFT polymerization and click chemistry: an efficient approach to surface modification. Macromol. Rapid Commun. 2007, 28, 2084-2089.

[94] Li, H.; Cheng, F. A. M. Duft and A. Adronov, Functionalization of single-walled carbon nanotubes with welldefined polystyrene by "click" coupling. J. Am. Chem. Soc., 2005, 127, 14518-14524.

[95] Li, H.; Adronov, A. Water-soluble SWCNTs from sulfonation of nanotube-bound polystyrene. Carbon 2007, 45, 984-990.

[96] Zhang, Y.; He, H.; Gao, C.; Wu, J. Covalent layer-by-layer functionalization of multiwalled carbon nanotubes by click chemistry. Langmuir 2009, 25,5814-5824.

[97] W.-B. Zhang, Y. Tu, R. Ranjan, R. M. Van Horn, S. Leng, J. Wang, M. J. Polce, C. Wesdemiotis, R. P. Quirk, G. R. Newkome and S. Z. D. Cheng. "Clicking” fullerene with polymers: synthesis of [60] fullerene end-capped polystyrene. Macromolecules 2008, 41,515-517.

[98] Li. Y.; Benicewicz, B. C. Functionalization of silica nanoparticles via the combination of surface-initiated RAFT polymerization and click reactions, Macromolecules 2008, 41, 7986-7992.

[99] Devaraj, N. K.; Collman, J. P. Copper catalyzed azide-alkyne cycloadditions on solid surfaces: applications and future directions. QSAR Comb. Sci. 2007, 26, 1253-1260.

[100] Ostaci, R.V.; Damiron, D.; Capponi, S.; Vignaud,G.; Leger, L.; Grohens, Y.; Drockenmuller, E. Polymer brushes grafted to "passivated" silicon substrates using click chemistry. Langmuir, 2008, 24, 2732-2739.

[101] Sawoo, S.; Dutta, P.; Chakraborty, A.; Mukhopadhyay, R.; Bouloussa, O.; Sarkar, A. A new bio-active surface for protein immobilisation viacopper-free 'click' between azido SAM and alkynyl Fischer carbene complex. Chem. Commun. 2008, 5957-5959.

[102] Salvio, R.; Krabbenborg, S.; Naber, W. J. M.; Velders, A. H.; Reinhoudt, D. N.; van der Wiel, W. G. The formation of large-area conducting graphene-like platelets. Chem.Eur. J. 2009, 15, 8235-8240.

[103] Allen, M. J.; Tung, V. C.; Kaner, R. B. Honeycomb carbon: a review of graphene. Chem. Rev. 2010, 110, $132-145$

[104] Braunecker, W. A.; Matyjaszewski, K. Controlled/living radical polymerization: features, developments and perspectives. Prog. Polym. Sci., 2007, 32, 93-146

[105] Matyjaszewski, K.; Braunecker, W. A. Radical polymerization. In Macromolecular Engineering: from Precise Macromolecular Synthesis to macroscopic Materials Properties and Applications. Matyjaszewski, K.; Gnanou, Y.; Leibler, L.; Eds; Wiley-VCH, Weinheim, Germany, 2007.

[106] Matyjaszewski, K.; Davis, T. P. Future Outlook and perspectives for radical polymerization. In Handbook of Radical Polymerization. Matyjaszewski, K.; Davis, T. P.; Eds., Wiley, New York, 2002.

[107] Moad, G.; Chiefari, J.; Chong, Y. K.; Krstina,J.; Mayadunne, R. T. A.; Postma, A.; Rizzardo, E.; Thang, S. H. Living free radical polymerization with reversible addition - fragmentation chain transfer (the life of RAFT). Polym. Int., 2000, 49, 993-1001

[108] Rizzardo, E.; Chiefari, J.; Mayadunne R.; Moad, G.; Thang,S. Tailored polymer architectures by reversible addition-frasmentation chain transfer. Macromol. Symp. 2001, 174, 209-2012.

[109] Cunningham, M. F. Controlled/living radical polymerization in aqueous dispersed systems. Prog. Polym. Sci. 2008, 33, 365-398.

[110] Lowe,B.; McCormick, C.L. Reversible addition-fragmentation chain transfer (RAFT) radical polymerization and the synthesis of water-soluble (co)polymers under homogeneous conditions in organic and aqueous media. Prog. Polym. Sci. 2007, 32, 283-351.

[111] Kamigaito, M.; Ando, T.; Sawamoto, M. Metal-catalyzed living radical polymerization, Chem. Rev. 2001, 101,3689-3745;

[112] Matyjaszewski K.; Xia, J. Atom transfer radical polymerization. Chem. Rev. 2001, 101,2921-2990;

[113] Wang, J.S.; Matyjaszewski, K. Controlled/" living" radical polymerization. atom transfer radical polymerization in the presence of transition-metal complexes. J. Am. Chem. Soc.1995, 117, 5614-5615;

[114] Matyjaszewski, K.; Tsarevsky, N. V. Nanostructured functional materials prepared by atom transfer radical polymerization. Nat.Chem. 2009, 1, 276-288;

[115] Tsarevsky, N. V.; Matyjaszewski, K. "Green” atom transfer radical polymerization: from process design to preparation of well-defined environmentally friendly polymeric materials. Chem. Rev. 2007, 107, 2270 2299.

[116] Georges, M. K.; Veregin, R. P. N.; Kazmaier, P. M.; Hamer, G. K. Narrow molecular weight resins by a freeradical polymerization process. Macromolecules 1993, 26, 2987-2988.

[117] Hawker, C. J.; Bosman, A. W.; Harth, E. New polymer synthesis by nitroxide mediated living radical polymerizations. Chem. Rev. 2001, 101, 3661-3688.

[118] Jakubowski, W.; Matyjaszewski, K. Activator generated by electron transfer for atom transfer radical polymerization. Macromolecules 2005, 38, 4139-4416.

[119] Arehart,S.V.; Matyjaszewski, K. Atom transfer radical copolymerization of styrene and $n$-butyl acrylate. Macromolecules 1999, 32,2221-2231. 
Amna and Ozturk, Org. Commun. (2021) 14:2 97-120

[120] Jakubowski, W.; Min, K.; Matyjaszewski, K. Activators regenerated by electron transfer for atom transfer radical polymerization of styrene. Macromolecules 2006, 39, 39-45.

[121] Jakubowski, W.; Matyjaszewski, K. Activators regenerated by electron transfer for atom-transfer radical polymerization of (meth)acrylates and related block copolymers. Angew. Chem., Int. Ed. 2006, 45, 44824486.

[122] Matyjaszewski,K.; Jakubowski, W.; Min, K.; Tang, W.; Huang, J. Y.; Braunecker, W. A.; Tsarevsky, N. V. Diminishing catalyst concentration in atom transfer radical polymerization with reducing agents. Proc. Natl. Acad. Sci. U. S. A. 2006, 103, 15309-15314.

[123] Matyjaszewski, K.;. Qiu, J.; Tsarevsky, N. V.; Charleux, B. Atom transfer radical polymerization of $n$-butyl methacrylate in an aqueous dispersed system: a miniemulsion approach. J. Polym. Sci., Polym. Chem. Ed. 2000, 38, 4724-4734.

[124] Pintauer,T.; Matyjaszewski, K. Structural aspects of copper catalyzed atom transfer radical polymerization. Coord. Chem. Rev. 2005, 249, 1155-1184.

[125] Min,K.; Matyjaszewski, K.; Atom transfer radical polymerization in aqueous dispersed media. Cent. Eur. J. Chem. 2009, 7, 657-674.

[126] Matyjaszewski, K. Introduction to living polymeriz. Living and/or controlled polymerization. J. Phys. Org. Chem. 1995, 8, 197-207;

[127] Matyjaszewski, K. Mechanistic and synthetic aspects of atom transfer radical polymerization. J. Macromol. Sci., Pure Appl. Chem. 1997, A34, 1785-1801.

[128] Qiu, J.; Matyjaszewski, K.; Thouin, L.; Amatore,C. Cyclic voltammetric studies of copper complexes catalyzing atom transfer radical polymerization. Macromol. Chem. Phys. 2000, 201, 1625-1631.

[129] Matyjaszewski, K.; Jo, S.M.; Paik H. J.; Shipp, D. A. An Investigation into the CuX/2,2'-bipyridine (X = $\mathrm{Br}$ or $\mathrm{Cl}$ ) mediated atom transfer radical polymerization of acrylonitrile. Macromolecules 1999, 32, 64316438.

[130] Matyjaszewski, K.; Paik, H. J.; Zhou. P.; Diamanti, S. J. Determination of Activation and Deactivation Rate Constants of Model Compounds in Atom Transfer Radical Polymerization. Macromolecules 2001, 34, 15, 5125-5131.

[131] Matyjaszewski, K. Macromolecular engineering: From rational design through precise macromolecular synthesis and processing to targeted macroscopic material properties. Prog. Polym. Sci. 2005, 30, 858-875.

[132] Lutz, J.F.; Lehn, J.M.; Meijer, E.W.; Matyjaszewski, K. From precision polymers to complex materials and systems. Nat. Rev. Mater. 2016, 1, 16024.

[133] Golas, P.L.; Matyjaszewski, K. Marrying click chemistry with polymerization: expanding the scope of polymeric materials. Chem. Soc. Rev. 2010, 39, 1338-1354.

[134] Xue, W.; Wang, J.; Wen, M.; Chen, G.; Zhang, W. Integration of CuAAC polymerization and controlled radical polymerization into electron transfer mediated "click-radical" concurrent polymerization. Macromol. Rapid Commun. 2017, 38, 1600733.

[135] Han, D.; Tong, X.; Zhao, Y. One-pot synthesis of brush diblock copolymers through simultaneous ATRP and click coupling. Macromolecules 2011, 44, 5531-5536.

[136] Xu, B.; Feng, C.; Huang, X. A versatile platform for precise synthesis of asymmetric molecular brush in one shot. Nat. Commun. 2017, 8, 333. doi:10.1038/s41467-017-00365-2

[137] Cheng, C.; Bai, X.; Zhang, X.; Chen, M.; Huang, Q.; Hu, Z.; Tu, Y. Facile synthesis of block copolymers from a cinnamate derivative by combination of AGET ATRP and click chemistry. Macromol. Res. 2014, 22, 1306-1311.

[138] Yao, F.; Xu, L.; Fu, G.D.; Lin, B. Sliding-graft interpenetrating polymer networks from simultaneous "click chemistry" and atom transfer radical polymerization. Macromolecules 2010, 43, 9761-9770.

[139] Zhang, W.; Xue, W.; Ming, W.; Weng, Y.; Chen, G.; Haddleton, D.M. Regenerable-catalyst-aided, opened to air and sunlight-driven "CuAAC\&ATRP" concurrent reaction for sequence-controlled copolymer. Macromol. Rapid Commun. 2017, 38, 1700511.

[140] Zhu, H.; Chen, G.; Zhang, Z.; Zhou, N.; Zhang, W.; Zhu, X. Fe(0) powder-catalyzed one-pot reaction: concurrent living radical polymerization and click chemistry for topological polymers. Polym. Chem. 2015, 6, 4794-4800.

[141] Xu, B.; Feng, C.; Huang, X.; A versatile platform for precise synthesis of asymmetric molecular brush in one shot. Nature Commun. 2017, 8. Article number 333. Doi:10.1038/s41467-017-00365-2

[142] Xue,W.; Wang, J.; Wen, M.; Chen, G.; Zhang, W. Integration of CuAAC polymerization and controlled radical polymerization into electron transfer mediated "click-radical" concurrent polymerization. Macromol. Rapid Commun. 2017, 38, 1600733.

[143] Qin, A.; Lam, J. W. Y.; Tang, B. Z. Click polymerization. Chem. Soc. Rev. 2010, 39, 2522-2544.

[144] Barner-Kowollik, C.; Du Prez, F. E.; Espeel, P.; Hawker, C. J.; Junkers, T.; Schlaad, H.; Van Camp, W. "clicking" polymers or just efficient linking: what is the difference? Angew. Chem. Int. Ed. 2011, 50, 60-62. 
[145] Wu, W.; Tang, R.; Li, Q.; Li, Z. Functional hyperbranched polymers with advanced optical, electrical and magnetic properties. Chem. Soc. Rev. 2015, 44, 3997-4022.

[146] Martens, S.; Holloway, J. O.; Du Prez, F. E. Click and click inspired chemistry for the design of sequencecontrolled polymers. Macromol. Rapid Commun. 2017, 38, 1700469.

[147] Huang, D.; Liu, Y.; Qin, A.; Tang, B. Z. Recent advances in alkyne-based click polymerizations. Polym. Chem. 2018, 9, 2853-2867.

[148] Li, B.; Huang, D.; Qin, A.; Tang, B. Z. Progress on catalytic systems used in click polymerization. Macromol. Rapid Commun. 2018, 39, 1800098.

[149] Du, J.; Huang, D.; Li, H.; Qin, A.; Tang, B.Z.; Li, Y. Catalyst-free click polymerization of thiol and activated internal alkynes: a facile strategy toward functional poly( $\beta$-thioacrylate)s. Macromolecules 2020, 53, 4932-4941.

[150] Wu, W.; Tang, R.; Li, Q.; Li, Z. Functional hyperbranched polymers with advanced optical, electrical and magnetic properties. Chem. Soc. Rev. 2015, 44, 3997-4022.

[151] Zheng, Y.; Li, S.; Weng, Z.; Gao, C. Hyperbranched polymers: advances from synthesis to applications. Chem. Soc. Rev. 2015, 44,4091-4130.

[152] Sun, F.; Luo, X.; Kang, L.; Peng, X.; Lu, C. Synthesis of hyperbranched polymers and their applications in analytical chemistry. Polym. Chem. 2015, 6, 1214-1225.

[153] Gurunathan, T.; Mohanty, S.; Nayak, S. K. Hyperbranched polymers for coating applications: a review. Polym.-Plast. Technol. Eng. 2015, 55, 92-117.

[154] Wang, D.; Zhao, T.; Zhu, X.; Yan, D.; Wang, W. Bioapplications of hyperbranched polymers. Chem. Soc. Rev. 2015, 44, 4023-4071.

[155] Zhu, Q.; Qiu, F.; Zhu, B.; Zhu, X. Hyperbranched polymers for bioimaging. RSC Adv. 2013, 3, $2071-2083$.

[156] Feng, G.; Liang, J.; Liu, B. Hyperbranched conjugated polyelectrolytes for biological sensing and imaging. Macromol. Rapid Commun. 2013, 34, 705-715.

[157] Shih, H. M.; Wu, R. C.; Shih, P. I.; Wang, C. L.; Hsu, C. S. Synthesis of fluorene-based hyperbranched polymers for solution-processable blue, green, red, and white light-emitting devices. J. Polym. Sci., Part A: Polym. Chem. 2012, 50, 696-710.

[158] Sunder, A.; Hanselmann, R.; Frey, H.; Mülhaupt, R. Synthesis of hyperbranched polyglycerols by ringopening multibranching polymerization. Macromolecules 1999, 32, 4240-4246.

[159] Chen, H.; Kong, J. Hyperbranched polymers from A2 + B3 strategy: recent advances in description and control of fine topology. Polym. Chem. 2016, 7, 3643-3663.

[160] Han, J.; Zhao, B.; Gao, Y.; Tang, A.; Gao, C. Sequential click synthesis of hyperbranched polymers via the A2 + CB2 approach. Polym. Chem. 2011, 2, 2175-2178.

[161] Zhou, Z.; Yan, D. Kinetic Theory of self-condensing vinyl polymerization. Sci. China: Chem. 2010, 53, 2429-2439.

[162] Chen, Y.; Wang, L.; Yu, H.; Zhao, Y.; Sun, R.; Jing, G.; Huang, J.;Khalid, H.; Abbasi, N. M.; Akram, M. Synthesis and application of polyethylene-based functionalized hyperbranched polymers. Prog. Polym. Sci. 2015, 45, 23-43.

[163] Segawa, Y.; Higashihara, T.; Ueda, M. Synthesis of hyperbranched polymers with controlled structure. Polym. Chem. 2013, 4,1746-1759.

[164] Wang, D.; Jin, Y.; Zhu, X.; Yan, D. Synthesis and applications of stimuli-responsive hyperbranched Polymers. Prog. Polym. Sci. 2017, 64, 114-153.

[165] Liu, G.; Chen, P.; Tang, R.; Li, Z. Synthesis and characterization of dendronized hyperbranched polymers through the "A3+B2" Approach. Sci. China: Chem. 2016, 59, 1561-1567.

[166] He, B.; Zhen, S.; Wu, Y.; Hu, R.; Zhao, Z.; Qin, A.; Tang, B. Z. Cu(I)-Catalyzed amino-yne click polymerization. Polym. Chem. 2016, 7, 7375-7382.

[167] He, B.; Su, H.; Bai, T.; Wu, Y.; Li, S.; Gao, M.; Hu, R.; Zhao, Z.;Qin, A.; Ling, J.; Tang, B. Z. Spontaneous apmino-yne click polymerization: a powerful tool toward regio- and stereospecific Poly( $\beta$-aminoacrylate $) \mathrm{s}$. J. Am. Chem. Soc. 2017, 139, 5437-5443.

[168] Chen, X.; Hu, R.; Qi, C.; Fu, X.; Wang, J.; He, B.; Huang, D.; Qin, A.; Tang, B. Z. Ethynylsulfone-based spontaneous amino-yne click polymerization: a facile tool toward regio- and stereoregular dynamic polymers. Macromolecules 2019, 52, 4526-4533.

[169] He, B.; Zhang, J.; Wang, J.; Wu, Y.; Qin, A.; Tang, B.Z. Preparation of multifunctional hyperbranched poly( $\beta$-aminoacrylate)s by spontaneous amino-yne click polymerization. Macromolecules 2020, 53, $5248-5254$

[170] Obhi, N. K.; Peda, D. M.; Kynaston, E. L; Seferos, D. S. Exploring the graft-to synthesis of all-conjugated comb copolymers using azide-alkyne click chemistry. Macromolecules 2018, 51, 8, 2969-2978.

[171] Kolb, H.C.; Sharpless, K. B. The growing impact of click chemistry on drug discovery, Drug Discov. Today DDT, 2003, 8, 1128-1137. 
Amna and Ozturk, Org. Commun. (2021) 14:2 97-120

[172] Teodorescu, F.; Rolland, L.; Ramarao, V.; Abderrahmani, A.; Mandler, D.; Boukherroub, R.; Szunerits, S. Electrochemically triggered release of human insulin from an insulin-impregnated reduced graphene oxide modified electrode. Chem. Commun. 2015, 75, 14167-14170.

[173] Szunerits, S.; Teodorescu, F.; Boukherroub, R. Electrochemically triggered release of drugs. Eur. Polym. J. 2016, 83, 467-477.

[174] Boulahneche, S.; Jijie, R.; Barras, A.; Chekin, F.; Singh, S. K.; Bouckaert, J.; Medjram, M. S.; Kurungot, S.; Boukherroub, R.; Szunerits, S. On demand electrochemical release of drugs from porous reduced graphene oxide modified flexible electrodes. J. Mater. Chem. B 2017, 5, 6557-6565.

[175] Hu, S. H.; Fang, R. H.; Chen, Y. W.; Liao, B. J.; Chen, I. W.; Chen, S. Y. Photoresponsive protein-grapheneprotein hybrid capsules with dual targeted triggered drug delivery approach for enhanced tumor therapy. Adv. Funct. Mater. 2014, 24, 4144-4155.

[176] Wang, C.; Mallela, J.; Garapati, U. S.; Ravi, S.; Chinnasamy, V.; Girard, Y.; Howell, M.; Mohapatra, S. M. A chitosan-modified graphene nanogel for noninvasive controlled drug release. Nanomedicine 2013, 9, 903911.

[177] Teodorescu, F.; Oz, Y.; Quéniat, G.; Abderrahmani, A.; Foulon, C.; Lecoeur, M.; Sanyal, R.; Sanyal, A.; Boukherroub, R.; Szunerits, S. Photothermally triggered on-demand insulin release from reduced graphene oxide modified hydrogels. J. Controlled Release 2017, 246, 64-173.

[178] Teodorescu, F.; Quéniat, G.; Foulon, C.; Lecoeur, M.; Barras, A.; Boulahneche, S.; Medjram, M. S.; Hubert, T.; Abderrahmani, A.; Boukherroub, R.; Szunerits, S. Transdermal skin patch based on reduced graphene oxide: a new approach for photothermal triggered permeation of ondansetron across porcine skin. J. Controll. Releas. 2017, 245, 137-146.

[179] Goenka, S.; Sant, V.; Sant, S. Graphene-based nanomaterials for drug delivery and tissue engineering. $J$. Controll. Releas. 2014, 173, 75-88.

[180] Matteini, P.; Tatini, F.; Cavigli, L.; Ottaviano, S.; Ghini, G.; Pini, R. Graphene as a photothermal switch for controlled drug release. Nanoscale 2014, 6, 7947-7953.

[181] Guo, C. X.; Ng, S. R.; Khoo, S. Y.; Zheng, X.; Chen, P.; Li, C. M. RGD-peptide functionalized graphene biomimetic live-cell sensorfor real-time detection of nitric oxide molecules. ACS Nano 2012, 6, 6944-6951.

[182] Xu, L. Q.; Wang, L.; Zhang, B.; Lim, C. H.; Chen, Y.; Neoh, K. G.; Kang, E.; Fu, G. D. Functionalization of reduced graphene oxide nanosheets via stacking interactions with the fluorescent and water-soluble perylene bisimide-containing polymers. Polymer 2011, 52,2376-2383.

[183] Kaminska, I.; Barras, A.; Coffinier, Y.; Lisowski, W.; Roy, S.; Niedziolka-Jonsson, J.; Woisel, P.; Lyskawa, J.; Opallo, M.; Siriwardena, A.; Boukherroub, R.; Szunerits, S. Preparation of a responsive carbohydratecoated biointerface based on graphene/azido-terminated tetrathiafulvalene nanohybrid material. ACS Appl. Mater. Interfaces 2012, 4, 5386-5393.

[184] Kaminska, I.; Das, M. R.; Coffinier, Y.; Niedziolka-Jonsson, J.; Woisel, P.; Lyskawa, J.; Opallo, M.; Boukherroub, R.; Szunerits, S. Reduction and functionalization of graphene oxide sheets using biomimetic dopamine derivatives in one step. ACS Appl. Mater. Interfaces 2012, 4, 1016-1020.

[185] Kaminska, I.; Das, M. R.; Coffinier, Y.; Niedziolka-Jonsson, J.; Woisel, P.; Opallo, M.; Szunerits, S.; Boukherroub, R. Preparation of graphene/tetrathiafulvalene nanocomposite switchable surfaces. Chem. Commun. 2012, 48, 1221-1223.

[186] Kaminska, I.; Qi, W.; Barras, A.; Sobczak, J.; Niedziolka-Jonsson, J.; Woisel, P.; Lyskawa, J.; Laure, W.; Opallo, M.; Li, M.; Boukherroub, R.; Szunerits, S. Thiol-yne click reaction on alkynyl-dopamine modified reduced graphene oxide (rGO). Chem. Eur. J. 2013, 19, 8673-8678.

[187] Qu, S.; Li, M.; Xie, L.; Huang, X.; Yang, J.; Wang, N.; Yang, S. Noncovalent functionalization of graphene attaching [6,6]-phenyl-C61-butyric acid methyl ester (PCBM) and application as electron extraction layer of polymer solar cells. ACS Nano 2013, 7, 4070-4081.

[188] Manova, R. K.; Pujari, S. P.; Weijers, C. A. G. M.; Zuilhof, H.; van Beek, T. A. Copper-free click biofunctionalization of silicon nitride surfaces via strain-promoted alkyne-azide cycloaddition reactions. Langmuir 2012, 28, 8651-8663.

[189] Oz,Y.; Barras, A.; Sanyal, R.; Boukherroub, R.; Szunerits, S.; Sanyal,A.; Functionalization of reduced graphene oxide via thiol-maleimide "click" chemistry: facile fabrication of targeted drug delivery vehicles. ACS Appl. Mater. Interfaces 2017, 9, 39, 34194-34203.

[190] Liu, X.; Gong, P.; Song, P.; Xie, F.; Miller, A. L.; Chenc S.; Lu, L. Rapid conjugation of nanoparticles, proteins and siRNAs to microbubbles by strain-promoted click chemistry for ultrasound imaging and drug delivery. Polym. Chem. 2019, 10, 705-717.

[191] Alcaraz, N.; Liu, Q.; Hanssen, E.; Johnston, A.; Boyd, B. J. Clickable cubosomes for antibody-free drug targeting and imaging applications. Bioconjugate Chem. 2018, 29, 1, 149-157. 
[192] Bostan, M.S.; Senol, M.; Cig, T.; Peker, I.; Goren, A.C.; Ozturk, T.; Eroglu, M.S. Controlled release of 5aminosalicylicacid from chitosan based $\mathrm{pH}$ and temperature sensitive hydrogels. Int. J. Biological Macromolecul. 2013, 52, 177- 183.

[193] Osman, A.; Oner, E.T.; Eroglu, M.S. Novel levan and pNIPA temperature sensitive hydrogels for 5ASAcontrolled release. Carbohydrate Polymers 2017, 165, 61-70.

[194] Eyigor, A.; Bahadori, F.; Yenigun, V.B.; Eroglu, M.S. Beta-Glucan based temperature responsive hydrogels for 5-ASA delivery. Carbohydrate Polymers 2018, 201 454-463.

[195] Balakrishnan, B.; Banerjee. R. Biopolymer-based hydrogels for cartilage tissue engineering. Chem. Rev. 2011, 111, 4453-4474.

[196] Zhao, J.; Hussain, M.; Wang, M.; Li, Z.; He. N. Embedded 3D printing of multi-internal surfaces of hydrogels. Addit. Manuf. 2020, 32, 101097.

[197] Wang, T.; Qu, G.; Wang, C.; Cheng, Y.; Shang, J.; Zheng, J.; Feng, Z.; Chen, Q.; He, N.; Importance of polyacrylamide hydrogel diverse chains and cross-linking density for cell proliferation, aging, and death. Langmuir 2019, 35, 13999-14006.

[198] Zhu, J. J.; Guan, S.; Hu, Q.Q.; Gao, G. H.; Xu, K.; Wang, P. X. Tough and pH-sensitive hydroxypropyl guar gum/polyacrylamide hybrid double-network hydrogel. Chem. Eng. J. 2016, 306, 953-960.

[199] Roy, S. G.; Kumar, A.; De, P. Amino acid containing cross-linked co-polymer gels: pH, thermo and salt responsiveness. Polymer 2016, $85,1-9$.

[200] P. Li, J. Zhang, C. M. Dong, Photosensitive poly(o-nitrobenzyloxycarbonyl-L-lysine)-b-PEO polypeptide copolymers: synthesis, multiple self-assembly behaviors, and the photo/pH-thermo-sensitive hydrogels. Polym. Chem. 2017, 8, 7033-7043.

[201] Yin, S.; Ma, Z. F. "Smart” sensing interface for the improvement of electrochemical immunosensor based on enzyme-Fenton reaction triggered destruction of $\mathrm{Fe}^{3+}$ cross-linked alginate hydrogel. Sens. Actuators B 2019, 281, 857-863.

[202] Kumar, C. S. S. R.; Mohammad, F. Magnetic nanomaterials for hyperthermia-based therapy and controlled drug delivery. Adv. Drug Delivery Rev. 2011, 63,789-808.

[203] Cheng, X.; Jin, Y.; Sun, T.; Qi, R.; Li, H.; Fan, W. An injectable, dual pH and oxidation-responsive supramolecular hydrogel for controlled dual drug delivery. Colloids Surf. B 2016, 141,44-52.

[204] Das, D.; Pal, S. Dextrin/poly (HEMA): pH responsive porous hydrogel for controlled release of ciprofloxacin. Int. J. Biol. Macromol. 2015, 72, 171-178.

[205] Grim, J. C.; Marozas, I. A.; Anseth, K. S. Thiol-ene and photo-cleavage chemistry for controlled presentation of biomolecules in hydrogels. J. Controll.Releas. 2015, 219,95-106.

[206] Lowe, A. B. Thiol-ene "click" reactions and recent applications in polymer and materials synthesis: a first update. Polym. Chem. 2014, 5, 4820-4870.

[207] Ding, H.; Li, B.; Liu, Z.; Liu, G.; Pu, S.; Feng, Y.; Jia, D.; Zhou, Y. Decoupled pH- and thermo-responsive injectable chitosan/PNIPAM hydrogel via thiol-ene click chemistry for potential applications in tissue engineering. Healthcare Mater. 2020, 9,2000454

[208] Astrain, G.C.; Avérous, L. Synthesis and evaluation of functional alginate hydrogels based on click chemistry for drug delivery applications. Carbohydrate Polymers 2018, 190, 271-280.

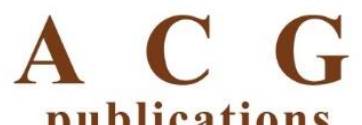

publications

(C) 2021 ACG Publications 